\title{
Biodegradation and Photodegradation of Vegetation-Derived Dissolved Organic Matter in Tidal Marsh Ecosystems
}

\author{
Sydney Shelton ${ }^{1,2}\left[\right.$ [D $\cdot$ Patrick Neale ${ }^{1}\left[\right.$ Andrew Pinsonneault ${ }^{1,3} \cdot$ Maria Tzortziou $^{4}$
}

Received: 23 September 2020 / Revised: 26 May 2021 / Accepted: 30 June 2021 / Published online: 20 October 2021

(c) Smithsonian Press 2021

\begin{abstract}
Tidal wetlands are a significant source of dissolved organic matter (DOM) to coastal ecosystems, which impacts nutrient cycling, light exposure, carbon dynamics, phytoplankton activity, microbial growth, and ecosystem productivity. There is a wide variety of research on the properties and sources of DOM; however, little is known about the characteristics and degradation of DOM specifically sourced from tidal wetland plants. By conducting microbial and combined UV exposure and microbial incubation experiments of leachates from fresh and senescent plants in Chesapeake Bay wetlands, it was demonstrated that senescent material leached more dissolved organic carbon (DOC) than fresh material $(77.9 \pm 54.3$ vs $21.6 \pm 11.8 \mathrm{mg} \mathrm{DOC} \mathrm{L}^{-1}$, respectively). Degradation followed an exponential decay pattern, and the senescent material averaged $50.5 \pm 9.45 \%$ biodegradable DOC (\%BDOC), or the loss of DOC due to microbial degradation. In comparison, the fresh material averaged a greater \%BDOC $(72.6 \pm 19.2 \%)$. Percent remaining of absorbance $(83.3 \pm 26.7 \%$ for fresh, $90.1 \pm 10.8 \%$ for senescent) was greater than percent remaining DOC, indicating that colored DOM is less bioavailable than non-colored material. Concentrations of DOC leached, \%BDOC, and SUVA280 varied between species, indicating that the species composition of the marsh likely impacts the quantity and quality of exported DOC. Comparing the UV + microbial to the microbial only incubations did not reveal any clear effects on \%BDOC but UV exposure enhanced loss of absorbance during subsequent dark incubation. These results demonstrate the impacts of senescence on the quality and concentration of DOM leached from tidal wetland plants, and that microbes combined with UV impact the degradation of this DOM differently from microbes alone.
\end{abstract}

Keywords Tidal marsh plants · Chromophoric dissolved organic carbon · Degradation · PARAFAC

\section{Introduction}

Tidal wetlands are a significant source of dissolved organic matter (DOM) to coastal ecosystems, consistently exporting dissolved organic carbon (DOC) through tidal flushing during

Communicated by Carolyn A. Currin

Patrick Neale

nealep@si.edu

1 Smithsonian Environmental Research Center (SERC), 647 Contees Wharf Road, Edgewater, MD 21037, USA

2 Rensselaer Polytechnic Institute, 110 8th Street, Troy, NY 12180, USA

3 University of Georgia, 325 Sanford Drive, Athens, GA 30602, USA

4 The City College of New York, City University of New York, 160 Convent Ave, New York, NY 10031, USA seasons of both low and high plant biomass (Tzortziou et al. 2008). Wetland sourced DOM is optically distinct and of different quality (in terms of its photo- and bio-reactivity) from estuarine DOM (Tzortziou et al. 2008; Logozzo et al. 2021). Thus, tidal wetlands are an important component of biogeochemical cycles and estuarine metabolism in coastal ecosystems (Hansell and Carlson 2015).

DOM, here operationally defined as a mixture of soluble organic compounds that can pass through a $0.2 \mu \mathrm{m}$ pore size filter, is constituted primarily of dissolved organic carbon (DOC), but also dissolved organic nitrogen and phosphorus (Hansell and Carlson 2015). The dynamics of DOM, thus, impact $\mathrm{C}, \mathrm{N}$, and $\mathrm{P}$ cycling, phytoplankton activity, microbial growth, and ecosystem productivity (Tzortziou et al. 2007; 2008; 2011; Fellman et al. 2010; Hansell and Carlson 2015; Logozzo et al. 2021). Thus, it is important to understand the sources of DOM, how DOM moves through ecosystems, and how DOM is transformed in aquatic environments. 
Sources of DOM in estuaries include terrestrial, marine, and estuarine primary production. Marine and terrestrial plants are biochemically distinct; therefore, land-derived organic components of DOM strongly influence DOM character (Hedges 1992). Some examples of terrestrial sources are plants, soils, and tidal sediments, all of which are present in wetlands that constantly exchange DOM with estuaries through runoff and tidal flushing. One theory in DOM export is the "fall dump" hypothesis, in which higher DOC concentrations are leached during the fall senescing period, indicating the importance of investigating both fresh and senescing material (Qi et al. 2017; Schiebel et al. 2018). Previous studies in Chesapeake Bay and North Carolina marshes showed that the greatest DOC concentrations in tidal marsh runoff are often observed in late summer and early fall (e.g., Tzortziou et al. 2008; Osburn et al. 2015). While vegetation-derived DOM characteristics typically vary based on the plant species, soilderived DOC typically has less seasonal and spatial variability (Wickland et al. 2007; Pinsonneault et al. 2020). In addition, soil-derived DOC is more refractory than DOC that has not been subject to soil processes (Wiegner and Seitzinger 2004).

Dissolved organic matter content is also an important determinant of the optical properties of natural waters. With a strong absorption and fluorescence signal in the UV-Visible range, the colored, or chromophoric, component of DOM (CDOM) affects light attenuation and biogeochemical and photochemical processes across marine, coastal, and inland aquatic environments (Helms et al. 2008). Because CDOM optical properties depend on the amount and chemical composition of DOM, optical analyses can be used to track water mixing (Murphy et al. 2008) as well as DOM source material (Hansen et al. 2016).

To quantify the importance of DOC in coastal and global carbon cycles and budgets, many previous studies conducted detailed laboratory biodegradation and photodegradation incubation experiments. Some studies of streams and estuaries suggest that photodegradation plays a larger role in DOC removal than biodegradation alone and may even increase biolability (Moran et al. 2000; Lu et al. 2013; Logozzo et al. 2021). During degradation, terrestrial humic substances, as classified by fluorescence components, are preferentially lost (Moran et al. 2000; Lu et al. 2013). In contrast, biodegradation of salt marsh and seagrass leachates preferentially consumed the protein-like component (Wang et al. 2014). Additionally, the percent biodegradable DOC (\%BDOC) varied among leachates of peat bog species and was positively related to the relative amount of protein-like components but inversely related to the relative amount of humic components (Pinsonneault et al. 2016). Lastly, $\%$ BDOC tends to be higher for fresh material compared to aged material, such as peat and leaf litters (Fellman et al.,
2013; Pinsonneault et al. 2016). Fluorescence components may offer a broadly applicable metric to assess the wide range of biodegradability of plant leachates; however, there is a lack of data relevant to DOC derived from tidal marsh vegetation.

The literature includes a variety of additional experiments examining leaching dynamics of wetland plants (Balogh et al. 2006; Fischer et al. 2006; Qi et al. 2017), degradation of DOM within waters (Vodacek et al. 1997; Wiegner and Seitzinger 2004; Yamashita et al. 2008; Walker et al. 2013; Osburn et al. 2015; Medeiros et al. 2017), and degradation of DOM sourced from plant material (Wickland et al. 2007). Few studies, though, focus on the degradation of DOM sourced from wetland plants specifically, and most of these lack data on seasonality (e.g., Vähätalo and Wetzel, 2008; Hansen et al. 2016).

Using chemical, absorbance, and fluorescence techniques, this study aims to investigate the biodegradation and photodegradation of DOM leached from fresh and senescent plants common to Chesapeake Bay wetlands. These results will be especially applicable as they complement several other DOM studies that have been completed in the region, including a microbial and photodegradation investigation of CDOM exported from tidal marshes (Logozzo et al. 2021), an investigation of DOM sources within the nearby estuarine Rhode River using optical properties (Tzortziou et al. 2008), a spatial analysis of tidal marsh sourced CDOM in the Rhode River (Tzortziou et al. 2011), and a study on the role of marsh soils and salinity in controlling variability in the magnitude of DOC exchange at the tidal marsh-estuarine interface (Pinsonneault et al. 2020). Data from this study are also relevant to the carbon dynamics in a marsh-estuary hydrodynamic-biogeochemical model implemented in the Rhode River (Clark et al. 2020).

The objectives of this study are to (1) examine how DOM sourced from Chesapeake Bay wetland plants changes with time during exposure to microbes, as well as a combination of microbes and ultraviolet radiation, and (2) examine how these changes compare between fresh and senescent material. We hypothesize that (1) UV exposed material will be more labile, (2) senescent material will leach more DOM than fresh material in accordance with the "fall dump" hypothesis, and (3) that the DOM will become more refractory throughout the degradation process as labile material will be more readily degraded.

\section{Methodology}

\section{Site Description}

Samples were taken at Kirkpatrick Marsh (38 $52^{\prime} 35.4^{\prime \prime} \mathrm{N}$, $\left.76^{\circ} 32^{\prime} 57.1^{\prime \prime} \mathrm{W}\right)$, also known as the Global Change Research 
Wetland (GCReW), and Jug Bay wetlands $\left(38^{\circ} 47^{\prime} 05^{\prime \prime} \mathrm{N}\right.$, $76^{\circ} 42^{\prime} 06^{\prime \prime} \mathrm{W}$ ), which are both part of the Chesapeake Bay watershed (Fig. 1). Brackish and freshwater tidal marshes, similar to Kirkpatrick and Jug Bay wetlands, cover about $700 \mathrm{~km}^{2}$ along the shores of the Chesapeake (Cestti et al. 2003). Kirkpatrick Marsh is located near the Smithsonian Environmental Research Center along the Rhode River subestuary and is a typical high elevation (from 0.4 to $0.6 \mathrm{~m}$ above mean low water) marsh for Mid-Atlantic North America. A creek bisects the marsh, and it is primarily vegetated by Sporobolus pumilus (formerly Spartina patens), Distichlis spicata, Iva frutescens, and Scirpus olneyi. Kirkpatrick marsh is fully submerged about $2 \%$ of the time and drains an area of about $0.03 \mathrm{~km}^{2}$ (Jordan and Correll 1991). Located on the Patuxent River, Jug Bay is an inland freshwater tidal marsh which is highly influenced by urban and suburban development (Swarth et al. 2013). It is predominantly vegetated by Leersia oryzoides, Hibiscus moscheutos, Peltandra virginica, Phragmites australis, Polygonum arifolium, and Typha $\times$ glauca (high marsh) and non-persistent emergent Nuphar lutea, Pontederia cordata, and Zizania aquatica (low marsh) (Swarth et al. 2013). The growing season for both marshes is approximately from May through October. Green biomass peaks in July and plants start to senesce in August (Curtis et al. 1989).

\section{Sample Collection}

Fresh cuttings were collected from a variety of wetland plant species during July of 2017. From Kirkpatrick marsh (GCReW), three square (S. americanus), common reed ( $P$. australis), and cordgrass (S. pumilus) were collected. From Jug Bay wetlands, yellow water lily (N. lutea), cattail (T. angustifolia), and rose mallow (H. moschuetos) were collected. Both leaf and stem samples were collected for fresh $T$. angustifolia, $N$. lutea, H. moschuetos, and P. australis. Stem samples were collected from S. americanus and S. pumilus. Senescent plant material was sampled during the second week of September 2019. Cattail (T. angustifolia, Jug Bay), cordgrass (S. pumilus, Kirkpatrick), common reed (P. australis, Kirkpatrick), high tide bush (I. frutescens, Kirkpatrick), and three square (S. americanus, Kirkpatrick) were all sampled. Cuttings were taken from senescent portions of the plants. Leaves were sampled from T. angustifolia, P. australis, and I. frutescens, whereas stem and leaf blades were sampled from S. americanus and S. pumilus. Not all species sampled for fresh material were sampled for senescent material as not all species were senescing at the time of collection, and senescing stems were not included due to limitations on how many samples could be accommodated during the UV-exposure experiment. Field-moist samples were stored in sealed freezer bags and transported back to the lab where they were stored at $4{ }^{\circ} \mathrm{C}$ awaiting analysis.

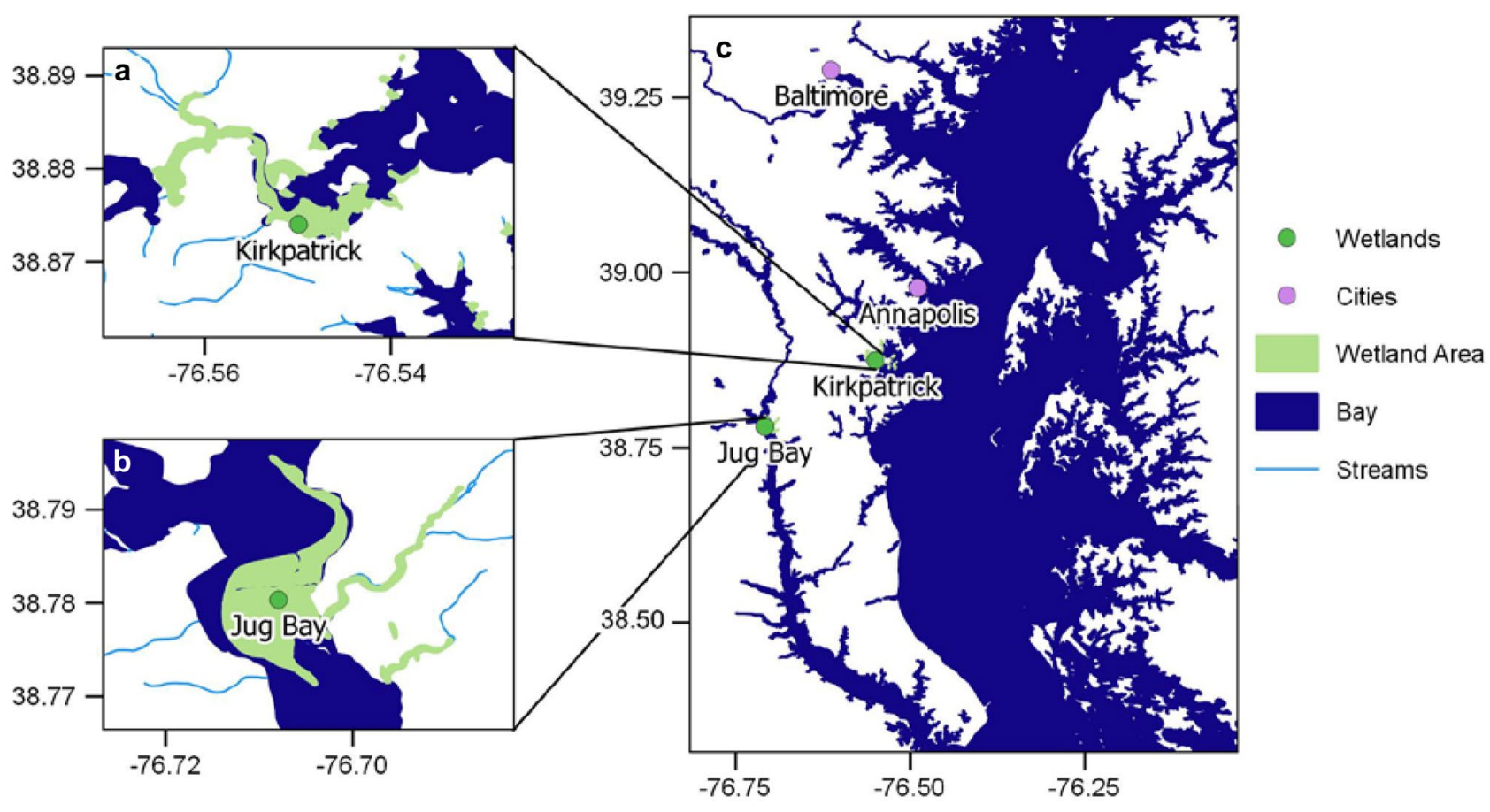

Fig. 1 a shows Kirkpatrick Marsh, which adjoins the Rhode River, b shows Jug Bay Wetlands, which adjoins the Patuxent River, and c shows the marsh sampling sites on the Chesapeake Bay. Marsh sites are denoted in green, while nearby cities are denoted in purple. Plotted using QGIS with data from the USGS Hydrography Dataset (U.S. Geologic Survey, National Geospatial Program 2020) 


\section{DOC Extraction}

Biodegradability and photodegradability were assessed using water extraction and incubation techniques modified from Pinsonneault et al. (2016) and Logozzo et al. (2021). Separate incubations were conducted for the fresh and senescent material. In each case, unhomogenized field moist plant samples were soaked in deionized water at a 1:100 dry weight to water ratio. Wet to dry weight ratios were determined by measuring wet weight mass on a set of trial samples, then drying to constant weight at $60{ }^{\circ} \mathrm{C}$. These ratios were then applied to a new collection of wet material to determine the amount of material needed to obtain a 1:100 dry weight:water ratio in the incubation. The plants were soaked overnight $(\sim 17 \mathrm{~h})$ at approximately $20^{\circ} \mathrm{C}$ in the dark. The following day, the leachates were filtered through Whatman glass fiber filters $(\mathrm{GF} / \mathrm{F}, 0.7 \mu \mathrm{m})$ to remove particulates and stored at $4{ }^{\circ} \mathrm{C}$. To isolate DOC, the leachates were further filtered through $0.2 \mu \mathrm{m}$ Nuclepore filters. This filtering process took place over 2 days. An aliquot was then taken to estimate the initial DOC concentration ([DOC]). The leachates were refrigerated at $4{ }^{\circ} \mathrm{C}$ for less than 2 days before the beginning of the incubation.

The day before the beginning of the incubation, an inoculum was prepared using the same procedure as Pinsonneault et al. (2016) to maintain comparability between studies. The inoculum used a composite of all of the plant species, which were added in approximately equal amounts, at a ratio of $4 \mathrm{~g}$ wet organic matter to $45 \mathrm{~mL}$ deionized water. The senescent inoculum used a composite of all of the senescing species used, whereas the fresh inoculum used a composite of all of the fresh plant species. In each case, the composite of the relevant plant cuttings were soaked overnight in filtered $(0.2 \mu \mathrm{m})$ DI water, for about $18 \mathrm{~h}$ in the dark at $20^{\circ} \mathrm{C}$. In order to avoid adding particulate matter to the incubation, the inoculum was filtered through ceramic wool before use.

\section{DOC Extract Incubations}

The incubation began by diluting the leachates to a DOC concentration $<20 \mathrm{mg} \mathrm{L}^{-1}$ DOC to prevent excess microbial growth. The leachates were initially diluted to about $15 \mathrm{mg}$ $\mathrm{L}^{-1}$, but the addition of the inoculum post-dilution increased the concentration by 3 (fresh) to 5 (senescent) $\mathrm{mg} \mathrm{L}^{-1}$. The concentrations attained post-dilution were $20.1 \pm 1.2 \mathrm{mg}$ $\mathrm{L}^{-1}$ (mean $\pm \mathrm{SD}$ ) for senescent material and $18.3 \pm 1.3 \mathrm{mg}$ $\mathrm{L}^{-1}$ for fresh, except for two fresh stem extracts that were already dilute (P. australis: $15.9 \mathrm{mg} \mathrm{L}^{-1}$ and $H$. moscheutos $9.6 \mathrm{~m} \mathrm{~L}^{-1}$ ). By comparison, the DOC concentration in surface water draining GCREW at low tide is in the range of 4 to $17 \mathrm{mg} \mathrm{L}^{-1}$ (Tzortziou et al. 2008; Menendez 2017). Median DOC in July is around $8 \mathrm{mg} \mathrm{L}^{-1}$. We report our results proportionally or in terms of initial DOC leached to address these differences. Deionized water was used to dilute these solutions. This deionized water was filtered to $0.2 \mu \mathrm{m}$ to minimize introduction of other microbial inocula. In the experimental plan based on Pinsonneault et al. (2016), it is assumed that once filtered through $0.2 \mu \mathrm{m}$, the material would be nearly sterile. Some bacteria can still pass through $0.2 \mu \mathrm{m}$ filters (e.g., Wang et al. 2007; Logozzo et al. 2021), but this residual quantity of bacteria is expected to be minor compared to the separately added inoculum.

The leachates were prepared by species, then divided among multiple types of incubations. Before the addition of the inoculum, a $40 \mathrm{~mL}$ sample was taken of the diluted leachate to serve as a pre-inoculation control. We then added $1 \%$ by volume of inoculum to each leachate. No nutrients were added to the leachates. This solution was then thoroughly mixed, and a $40 \mathrm{~mL}$ sample was taken to serve as a Day 1 sample for the UV + microbial incubation.

To prepare for the bacteria-only incubation, based on Pinsonneault et al. (2016), substrate for microbial growth was provided by placing two combusted glass fiber filters (Whatman GF/F), cut in half using sterilized scissors, in acid washed $500 \mathrm{~mL}$, wide mouthed, soda-lime glass jars ("Mason" jars). Triplicate Mason jars for each species were filled with $450 \mathrm{~mL}$ of leachate, and loosely covered with aluminum foil and incubated in the dark at $20{ }^{\circ} \mathrm{C}$. The jars were agitated daily.

The microbial (dark) incubations, conducted in triplicate for each species, were sampled on Days 1, 5, 8, 14, 28, and 42 (senescent material) and Days 1, 3, 7, 14, 28, and 56 (fresh material). The Day 1 sample was taken at the end of the incubation preparation process. On the other days, each jar was weighed then thoroughly agitated and a single 60 $\mathrm{mL}$ aliquot was removed from each Mason jar. The sample was then filtered through $0.45 \mu \mathrm{m}$ glass fiber syringe filters (Whatman GD/X) to exclude any particulate material from the added filters in the jars. The same syringe and filter was used for each species, and thoroughly rinsed between each species. Samples were stored in acid washed, combusted brown glass bottles at $4{ }^{\circ} \mathrm{C}$ in the dark until further processing.

The UV-exposed and microbial (UV + microbial) incubation followed the methodology of Logozzo et al. (2021). In order to conduct triplicate UV + microbial and dark control incubations for each species, three acid-washed FEP ("Teflon") bottles were filled with $100 \mathrm{~mL}$ of leachate with added inoculum. The Teflon bottles were irradiated from below in a UV exposure setup as described in Logozzo et al. (2021) for Days 1-8. The bottles were positioned on a UV-transmitting acrylic Plexiglas sheet that was placed approximately one inch above two Q-labs UVA340 lamps providing an average exposure of $8.7 \mathrm{~W} \mathrm{~m}^{-2}$. The $100 \mathrm{~mL}$ of filtrate filled the Teflon bottles to a depth of about $4 \mathrm{~cm}$. These bottles were inverted once per day, and their positions above the 
lamps sequentially displaced one position per day so that all bottles received the same exposure. The room was kept at $20{ }^{\circ} \mathrm{C}$, and the lamp was on $24 \mathrm{~h}$ per day which resulted in a daily UV exposure of about $750 \mathrm{~kJ} \mathrm{~m}^{-2}$. This is comparable to the daily incident exposure at SERC during September (Williamson and Neale, 2009). For the Day 1 results, we used the same measurements for the UV + microbial incubation and the senescent material microbial incubation due to evidence of microbial degradation during storage of the Day 1 sample of the UV + microbial incubation. More information is available in the Supplementary Material (S1). On Day 8, the Teflon bottles were removed from the UV exposure setup and sampled. About $40 \mathrm{~mL}$ of unfiltered leachate was transferred to a sample container; then, the Teflon bottles were stored in the dark incubation chamber at $20^{\circ} \mathrm{C}$ until Day 15 when final sampling occurred.

The UV + microbial bottles were paired with a separate microbial-only incubation in bottles of equivalent volume which we term the "dark" control. For this incubation, three acid washed then combusted brown glass bottles were filled with $100 \mathrm{~mL}$ of leachate with added inoculum, incubated in a dark chamber at $20^{\circ} \mathrm{C}$ and sampled on Days 1,8 , and 15 , the same as the Teflon bottles. There was no attempt at a bacteria-free incubation as studies have shown that a minor, but still important, microbial component passes through the $0.2 \mu \mathrm{m}$ filters (Wang et al. 2007; Logozzo et al. 2021).

The design for the UV exposure/microbial incubation (based on Logozzo et al. 2021) differed from the microbialonly incubation (based on Pinsonneault et al. 2016) because several characteristics of the latter approach made it unsuitable for an irradiance treatment. Most importantly, the Mason jars used for the microbial incubation are not fully UV transparent and the presence of the 4 filter halves that provide a substrate for microbial growth would interfere with the irradiation. Moreover, samples from the UV exposed/dark incubations were not filtered before analysis in order to avoid filtration artifacts which can arise after UV exposure of DOM (cf. Lu et al. 2013). While bacteria were present in these samples, preliminary tests using un-irradiated material showed that their presence did not cause analytical artifacts (Lu et al. 2013; Logozzo et al. 2021). Despite being unsuitable for an experiment with an irradiance treatment, the Pinsonneault et al. (2016) procedure was used for the microbial incubation for comparability with previous studies of biodegradability. The results of the microbial incubations are compared with the $100 \mathrm{~mL}$ dark bottle incubations to test for any effect of these methodological differences on the results.

\section{Sample Analyses}

Except for the DOC determinations on the initial leachate, all results reported are for the diluted material used in the incubations. The concentration of DOC was quantified using a Shimadzu TOC-L analyzer. Determinations followed the manufacturer's recommended protocol for non-purgeable organic carbon based on calibration with potassium hydrogen phthalate. A 0 - to $30-\mathrm{mg} \mathrm{L}^{-1}$ calibration curve was used, and blanks and standards were run every ten samples. Triplicate determinations were made on microbial incubation samples; duplicate determinations were run on UV exposed and dark control incubation samples so as to complete sample processing within 2 weeks. A Thermo Scientific Evolution 220 UV-Vis Spectrophotometer was used to measure room temperature samples' absorbance from 270 to $750 \mathrm{~nm}$ at a bandwidth of $2 \mathrm{~nm}$. Duplicate scans were run for each sample, with DI blanks every 10 samples. $\mathrm{a}_{\mathrm{CDOM}} \lambda$ was calculated from the optical density (OD) and path length $\left(l_{\mathrm{g}}\right.$, which for our measurements was $1 \mathrm{~cm}=0.01 \mathrm{~m}$ ):

$a_{C D O M} \lambda=2.303 \frac{O D}{l_{g}}$

The specific UV absorbance at $280 \mathrm{~nm}$, or SUVA280, was estimated as the ratio of $a_{C D O M} 280$ divided by the concentration of DOC. SUVA has been shown to be a useful proxy for DOM aromatic content and molecular weight (e.g., Chin et al. 1994; Weishaar et al. 2003).

A SPEX-Horiba Fluoromax-3 was used to measure Excitation-Emission Matrices (EEMs), synchronous fluorescence scans, and fluorescence indices (i.e. fluorescence index, freshness index, biological index, and humification index). Excitation intervals were $5 \mathrm{~nm}(240-600 \mathrm{~nm})$, and emission intervals were $2 \mathrm{~nm}(250-600 \mathrm{~nm})$. A DI EEM was measured for each set of sample EEMs; after the inner-filter corrections, the DI EEM was subtracted from the sample EEM which was then converted to Raman Units, using the area under the Raman scattering peak (excitation: $350 \mathrm{~nm}$ and emission: 318 to $427 \mathrm{~nm}$ ). Fluorescence spectra were corrected for inner-filter effect and Raman scattering using the drEEM toolbox version 0.2.0 (Murphy et al. 2013) in MATLAB (v. 2019b). Parallel factor analysis (PARAFAC) was used to deconstruct the fluorescence signal into underlying fluorescence components, or fluorophores, that relate to differences in DOM composition (Murphy et al. 2013).

\section{Statistics}

Statistics were conducted using the Matlab statistics toolbox. The Levene test was used to test for equal variances, and the Jarque-Bera test was used to test for a normal distribution. If these tests were met, a $t$ test was completed for all paired comparisons unless otherwise indicated. If not, the nonparametric Kruskal-Wallis test for differences in means of incubations was applied, the use of which is specifically noted in the text. The criterion for rejection of the null hypothesis was alpha $=0.05$, adjusted by the 
Bonferroni-Holm correction in cases of multiple species comparisons (Holm 1979). Tests were conducted using the means for each replicate incubation. Error is listed as standard deviation unless otherwise noted. Nonlinear regression models (time-series curve fits) were fitted to the concentration of DOC over the course of the incubation using an exponential decay function, of the form $a_{1} \exp (-k t)+a_{2}$, where $t$ is time in days, and $a_{1}, k$, and $a_{2}$ are fitted parameters. Parameters and their variances were estimated using the Matlab fitnlm function. These rates of degradation between fresh and senescent plant leachates were compared using a $t$ test. An ANOVA comparison followed by post hoc comparison (Tukey) was used to compare variables among species.

\section{Results}

\section{Biodegradable DOC in Marsh Plant Leachates}

The DOC concentration of the initial leachate, pre-dilution and pre-inoculum $\left([\mathrm{DOC}]_{0}\right)$, was significantly greater for the senescent extracts as a whole, with an average $( \pm \mathrm{SD})$ concentration of $77.9 \pm 54.3 \mathrm{mg}$ DOC L $\mathrm{L}^{-1}$, than the fresh extracts, which yielded $21.6 \pm 11.8 \mathrm{mg} \mathrm{DOC}^{-1}$ on average ( $p=0.0016$, Kruskal-Wallis Test). This trend was also observed in paired comparisons of fresh and senescent leachate for two of the four species in which both leachates were incubated, $S$. americanus and $P$. australis leaf, $(t$-test, $p<0.0001$ with a Bonferroni-Holm adjusted alpha $=0.0125$, and $p<0.0001$, adjusted alpha $=0.0167$, respectively). However, this relationship was not shown in the S. pumilus (t-test, $p=0.0317$, adjusted alpha $=0.025)$ and $T$. angustifolia leaf (Kruskal-Wallis test, $p=0.0495$ ) (Table 1; S2). The latter test did not meet the significance criterion as its rank order in the set of multiple comparisons follows the non-significant test of S. pumilus (Holm 1979).

Overall, fresh extracts showed the lowest amounts of DOC remaining at the end of the microbial (dark) incubation (i.e., greatest loss of DOC) relative to the initial concentration (Fig. 2; Table 2; S3). The DOC consumed during microbial-only incubations is commonly referred to as percent biodegradable DOC or \%BDOC. By the end of the incubation, the fresh material averaged $72.6 \pm 19.2 \%$ BDOC which is significantly greater than the \%BDOC of senescent material which averaged $50.5 \pm 9.45 \%$ $(p=0.0320)$. Again, \%BDOC was also significantly greater for fresh material in paired comparisons for all four species in which both fresh and senescent leachates were incubated, being higher in fresh leachates by $25.5 \%$ for S. americanus, $23.2 \%$ for S. pumilus, $21.2 \%$ for P. australis leaf, and $47.8 \%$ for T. angustifolia leaf $(p=0.0014$, $p=0.0033, p=0.0006, p<0.0001$, respectively, and minimum adjusted alpha $=0.0125$; Table 1 ). For all species, the concentration progressively decreased for roughly the

Table 1 Initial [DOC] $]_{0}$ (pre-dilution), \%BDOC, SUVA280 at Day 1, a300 at Day 1, and rate of degradation of extracts in microbial incubations, mean \pm standard deviation

\begin{tabular}{|c|c|c|c|c|c|}
\hline Samples & {$[\mathrm{DOC}]_{0}\left(\mathrm{mg} \mathrm{L}^{-1}\right)$} & $\mathrm{BDOC}(\%)$ & $\begin{array}{l}\operatorname{SUVA} 280(\mathrm{~L} \\
\left.\operatorname{mgDOC}^{-1} \mathrm{~m}^{-1}\right)\end{array}$ & $a 300\left(\mathrm{~m}^{-1}\right)$ & Rate of Degradation ${ }^{\mathrm{a}}\left(\mathrm{day}^{-1}\right)$ \\
\hline H. moschuetos leaf fresh & $21.1 \pm 10.5$ & $82.4 \pm 0.85$ & $0.752 \pm 0.010$ & $11.4 \pm 0.043$ & $0.06578 \pm 0.0095$ \\
\hline H. moschuetos stem fresh & $6.60 \pm 1.9$ & $69.7 \pm 1.1$ & $1.01 \pm 0.015$ & $7.22 \pm 0.062$ & $0.312 \pm 0.016$ \\
\hline I. frutescens leaf senescent & $155 \pm 1.1$ & $58.9 \pm 2.8$ & $4.61 \pm 0.091$ & $76.7 \pm 1.4$ & $0.235 \pm 0.028$ \\
\hline N. lutea leaf fresh & $13.7 \pm 4.8$ & $86.1 \pm 0.63$ & $0.640 \pm 0.0090$ & $9.29 \pm 0.067$ & $0.0723 \pm 0.0059$ \\
\hline N. lutea stem fresh & $41.6 \pm 4.3$ & $80.8 \pm 0.42$ & $0.226 \pm 0.00096$ & $2.85 \pm 0.030$ & $0.0845 \pm 0.0096$ \\
\hline P. australis leaf fresh & $41.9 \pm 4.3$ & $80.0 \pm 2.3$ & $0.518 \pm 0.010$ & $7.33 \pm 0.027$ & $0.0758 \pm 0.0077$ \\
\hline P. australis leaf senescent & $108 \pm 2.7$ & $58.8 \pm 2.0$ & $3.27 \pm 0.12$ & $51.9 \pm 0.53$ & $0.448 \pm 0.060$ \\
\hline P. australis stem fresh & $12.5 \pm 2.0$ & $75.4 \pm 1.1$ & $0.660 \pm 0.0091$ & $7.42 \pm 0.090$ & $0.154 \pm 0.011$ \\
\hline S. americanus fresh & $21.1 \pm 3.4$ & $72.7 \pm 0.86$ & $1.45 \pm 0.018$ & $20.0 \pm 0.030$ & $0.0776 \pm 0.0048$ \\
\hline S. americanus senescent & $69.2 \pm 0.56$ & $47.2 \pm 4.5$ & $3.97 \pm 0.018$ & $52.9 \pm 0.40$ & $0.332 \pm 0.051$ \\
\hline S. pumilus fresh & $15.9 \pm 2.3$ & $74.5 \pm 2.3$ & $2.06 \pm 0.024$ & $30.2 \pm 0.044$ & $0.428 \pm 0.020$ \\
\hline S. pumilus senescent & $21.3 \pm 0.37$ & $51.3 \pm 4.7$ & $3.40 \pm 0.14$ & $51.8 \pm 0.20$ & $0.564 \pm 0.10$ \\
\hline T. angustifolia leaf fresh & $16.1 \pm 4.9 *$ & $83.9 \pm 0.76$ & $0.589 \pm 0.0076^{*}$ & $8.51 \pm 0.15$ & $0.0664 \pm 0.0083$ \\
\hline T. angustifolia leaf senescent & $36.6 \pm 0.70 *$ & $36.1 \pm 3.3$ & $3.23 \pm 0.13 *$ & $51.1 \pm 0.36$ & $0.368 \pm 0.078$ \\
\hline T. angustifolia stem fresh & $25.8 \pm 5.0$ & $20.1 \pm 4.9$ & $0.858 \pm 0.0059$ & $8.88 \pm 0.038$ & $0.276 \pm 0.083$ \\
\hline
\end{tabular}

Bolded pairs indicate rejection of the null hypothesis of the $t$-test for paired comparisons of fresh vs senescent of the same species with $\alpha=$ 0.05 , adjusted by the Bonferroni-Holm correction. $a 300$ was omitted from paired comparisons because differences are determined, in part, by varying leachate dilution (see text). An expanded table with $p$-values is available in the Supplementary Material (S2)

* $p$-value of the paired comparison was calculated with Kruskal Wallis test instead of a t-test

${ }^{\text {a }}$ Standard error from curve fit 
Fig. 2 Percentage of DOC remaining in solution over the course of the 42- and 56-day incubations for a $S$. americanus, b $S$. pumilus, c $T$. angustifolia leaf, $\mathbf{d} T$. angustifolia stem, $\mathbf{e}$ $P$. australis leaf, $\mathbf{f} P$. australis stem, $\mathbf{g}$ H. moscheutos leaf, $\mathbf{h}$ $H$. moscheutos stem, i N. lutea leaf, $\mathbf{j} N$. lutea stem, and $\mathbf{k} I$. frutescens leaf. Each data point represents an average of the triplicate incubations. Triangles represent the fresh cutting extract data, circles represent the senescent cutting extract data, and error bars are standard deviation. In many cases, error bars are smaller than symbol. Lines represent fitted exponential decay models, which were fitted over the entire incubation. View Table 2 for associated $\mathrm{R}$-squared values
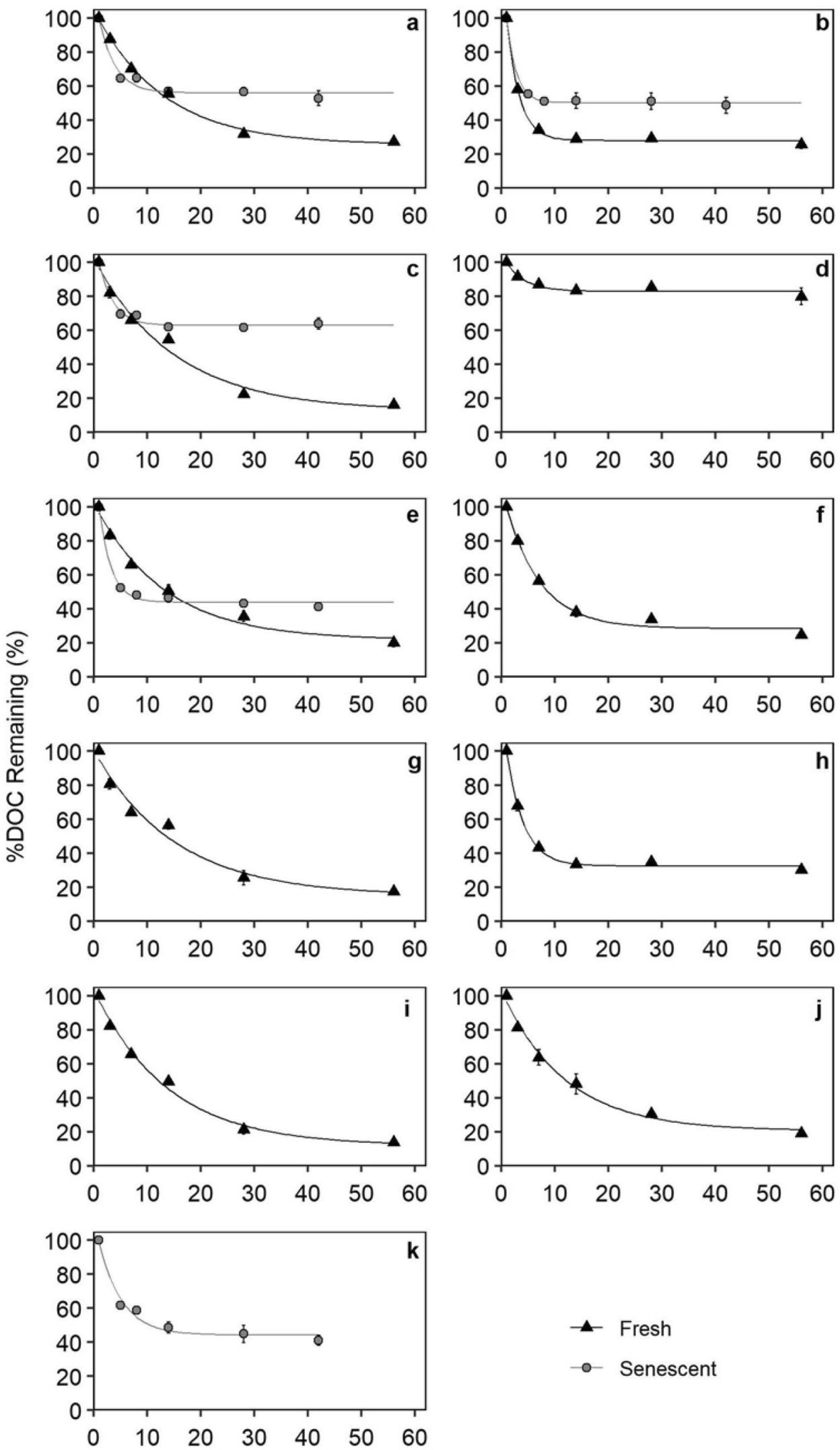

Fresh

Senescent 
Table 2 R-squared values for the fitted exponential decay models shown in Fig. 2. Plot is the associated plot in Fig. 2

\begin{tabular}{llll}
\hline Species & Incubation Type & Plot & R-squared \\
\hline S. americanus & Fresh & $\mathrm{a}$ & 0.993 \\
S. americanus & Senescent & $\mathrm{a}$ & 0.951 \\
S. pumilus & Fresh & $\mathrm{b}$ & 0.995 \\
S. pumilus & Senescent & $\mathrm{b}$ & 0.975 \\
T. angustifolia leaf & Fresh & $\mathrm{c}$ & 0.975 \\
T. angustifolia leaf & Senescent & $\mathrm{c}$ & 0.921 \\
T. angustifolia stem & Fresh & $\mathrm{d}$ & 0.835 \\
P. australis leaf & Fresh & $\mathrm{e}$ & 0.982 \\
P. australis leaf & Senescent & $\mathrm{e}$ & 0.975 \\
P. australis stem & Fresh & $\mathrm{f}$ & 0.990 \\
H. moscheutos leaf & Fresh & $\mathrm{g}$ & 0.967 \\
H. moscheutos stem & Fresh & $\mathrm{h}$ & 0.994 \\
N. lutea leaf & Fresh & $\mathrm{i}$ & 0.989 \\
N. lutea stem & Fresh & $\mathrm{j}$ & 0.977 \\
I. frutescens leaf & Senescent & $\mathrm{k}$ & 0.961 \\
\hline
\end{tabular}

first week of the incubation then approached a plateau. The lack of further decline showed that the material became more refractory during the incubation. In paired comparisons of the time series curve fits, the senescent material for three species had a more than fourfold greater rate of degradation than fresh material (S. americanus, $p<0.0001 ; P$. australis, $p<0.0001 ; T$. angustifolia, $p=0.0006$; minimum adjusted alpha $=0.0125$; Table 1); thus, for these species, the labile DOC sourced from the senescent material was consumed faster, even if a smaller fraction overall was labile. However, recall that the $[\mathrm{DOC}]_{0}$ of senescent material extracts was greater than fresh material extracts. When the incubation \%BDOC is applied to the original (undiluted) extract, the absolute amount of BDOC $\left(\mathrm{mg} \mathrm{L}^{-1}\right)$ was actually greater than in fresh extracts for two species ( $S$. americanus and P. australis) of the four compared (Fig. 3).

\section{Changes in Marsh Plant CDOM Absorption Properties}

The average Day 1 SUVA280 additionally varied significantly $(p<0.0001)$ between the fresh and senescent material, $0.88 \pm 0.53 \mathrm{~L}(\mathrm{mg} \mathrm{DOC})^{-1} \mathrm{~m}^{-1}$ and $3.69 \pm 0.59 \mathrm{~L}(\mathrm{mg} \mathrm{DOC})$ ${ }^{-1} \mathrm{~m}^{-1}$, respectively. This trend was also observed in all four of the species with both fresh and senescent leachates $(S$. americanus, $p<0.0001$ and adjusted alpha $=0.0167 ; S$. pumilus, $p=0.0002$ and adjusted alpha $=0.025 ; P$. australis, $p<0.0001$ and adjusted alpha $=0.0125 ;$ T. angustifolia, $p=0.0495$ (Kruskal-Wallis Test) and adjusted alpha $=0.05$; Table 1). Day 1 absorbance at $300 \mathrm{~nm}$ (a300) was not compared between the fresh and senescent material or between species as each leachate had a different dilution factor; however, the senescent material did have significantly more $\% a 300$ remaining compared to the fresh material $(90.1 \pm 10.8 \%$ and $83.3 \pm 26.7 \%$, respectively, $p=0.0183$, Kruskal-Wallis Test). Given the possibility that optical properties could be affected by dilution (the factor being 10 or greater in some cases), we did not estimate $a 300$ in the undiluted leachate. However even with the dilution, given the higher SUVA280, the absorbance of senescent material was consistently higher than that of the fresh material (Fig. 4). Additionally, as apparent in Fig. 4, our Day 1 absorbance spectra contain many deviations from the simple exponential fit that is often used to determine spectral slope and slope ratios; thus, we are not including this information in our results. These Day 1 spectra frequently contain offsets from the exponential shape which peak around 275 and $320 \mathrm{~nm}$. Absorbance spectra from the end of the microbial-only incubations more closely fit an exponential model. While the
Fig. 3 Biodegradable DOC, i.e., the total amount of extracted DOC that was labile by each species, representing the average of triplicate incubations. $\mathrm{BDOC}$ is $[\mathrm{DOC}]_{0}$ (pre-dilution) multiplied by \%BDOC. Black represents the fresh material, while medium grey represents the senescent material. a displays species where fresh and senescent material were incubated, while b displays species where either fresh or senescent material was incubated. Error bars are standard deviation
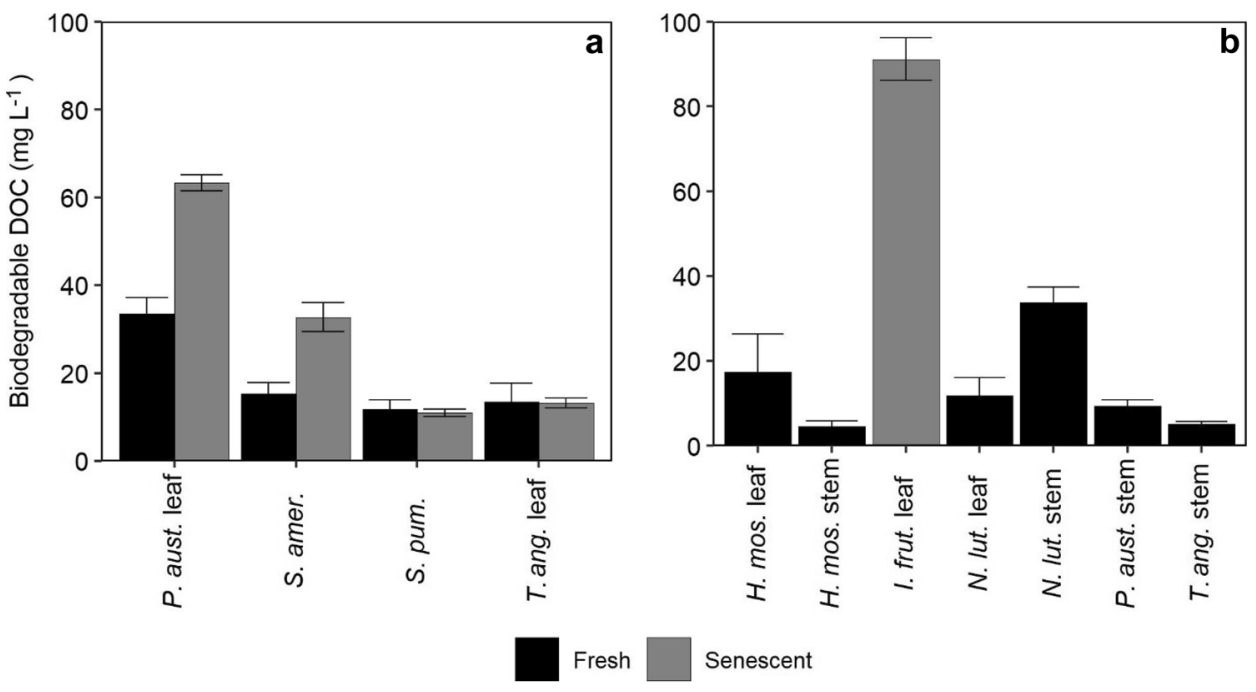
UV exposed + microbial incubation exhibits further deviation from the microbial-only incubation, this change was not recorded here using the slope ratio (Helms et al. 2008), as the slope ratio was not applicable to our initial curves. Qualitatively, it can be seen that over the incubation the proportion of long-wavelength absorbance increased, which is consistent with a decrease in spectral slope over time (Fig. 4). This trend was quantitatively confirmed when the curves were fit to an exploratory model containing both exponential and Gaussian components (available in the Supplementary Material; S4). The decrease in slope in the microbial-only incubations indicates that the material is being enriched with more aromatic, high molecular weight material.

$[D O C]_{0}, \%$ BDOC, and SUVA280 all varied between species. Full results of the ANOVA analysis are included in the Supplementary Material (S5). For the fresh material, differences in \%BDOC among species and between stem and leaf material in the same species were generally $<10 \%$ (27 of 45 comparisons). Extracts from leaves tended to have more \%BDOC than that from stems of the same species but the difference was small (4-13\%). The stem extract of $T$. angustifolia was the notable exception, having the least $\% \mathrm{BDOC}$ of all fresh extracts (difference $\geq 50 \%$ for all comparisons, $\mathrm{p}<0.0001$ ). Otherwise, the differences were greatest for the dicot species, H. moscheutos, with $\% \mathrm{BDOC}$ of the leaf extract greater by $13 \%$ compared to its stem extract $(\mathrm{p}=0.0001)$ and greater by $16 \%$ than $N$. lutea leaf extract $(\mathrm{p}<0.0001)$. Differences in $[\mathrm{DOC}]_{0}$ for fresh material were generally within the variability of the data ( 28 of 45 comparisons, $p=0.16$ to 1.00 ). For the remaining comparisons, difference in $[\mathrm{DOC}]_{0}$ were in the range $20-35 \mathrm{mg} \mathrm{L}^{-1}$ ( $\mathrm{p} \leq 0.001$ in 9 cases); however, there was no obvious pattern of stem vs leaf or monocots vs dicots (S5, Fresh DOC0). Contrary to DOC, SUVA280 varied among almost all species in the fresh incubation (40 of 45 comparisons, difference 0.1 to $1.8 \mathrm{~L}(\mathrm{mg} \mathrm{DOC})^{-1} \mathrm{~m}^{-1}$, $\mathrm{p}<0.0001)$. This suggests that while the quantity of DOC and \%BDOC in extracts from fresh material stays relatively similar with different marsh compositions, there are differences in DOC quality.
Fig. 4 Absorbance spectra for a Day 1 and $\mathbf{b}$ the final day of the incubation. Solid lines represent the fresh cutting extract incubation, which ended at Day 56; dashed lines represent the senescent extract incubation, which ended at Day 42; and dotted lines represent the UV + microbial incubation, which ended at Day 15

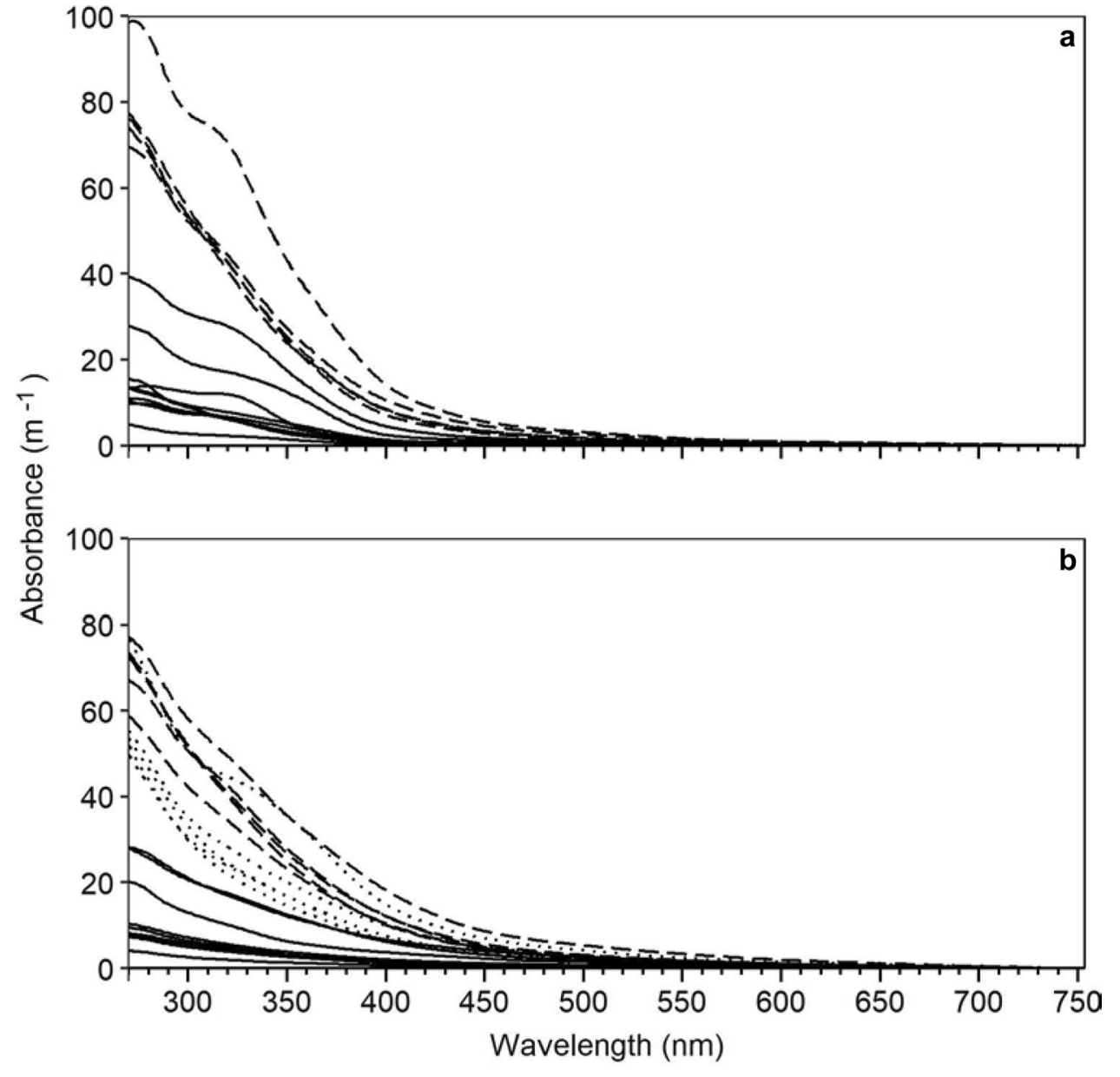

— Fresh - - Senescent $\cdots$ UV Exposed 
For the senescent material, $[\mathrm{DOC}]_{0}$ varied among all species, with the paired differences ranging from 32 to $133 \mathrm{mg}$ $\mathrm{L}^{-1}(\mathrm{p}<0.0001)$, except for the difference between $T$. angustifolia and S. pumilus extracts $\left(15 \mathrm{mg} \mathrm{L}^{-1}, \mathrm{p}<0.0001\right)$. I. frutescens leaf extract was 47 to $133 \mathrm{mg} \mathrm{L}^{-1}$ greater than the other extracts. \%BDOC was notably less for $T$. angustifolia leaf extract compared to the $I$. frutescens, $P$. australis, and $S$. pumilus extracts (lower by $>15 \%, \mathrm{p}=0.012$ to 0.006 ). In other comparisons, the difference in \%BDOC was $<11.7 \%$ ( $p>0.05$ ). Lastly, SUVA280 was somewhat variable among extracts of senescent material. I. frutescens had the highest $\left(4.61 \pm 0.09 \mathrm{~L}(\mathrm{mg} \mathrm{DOC})^{-1} \mathrm{~m}^{-1}\right)$ which was 0.64 higher than S. americanus $(\mathrm{p}=0.001)$ and more than 1.00 higher than other extracts $(\mathrm{p}<0.0001)$. On the other hand, SUVA280 was similar for T. angustifolia, P. australis, and S. pumilus extracts (range 3.2 to $3.4 \mathrm{~L}(\mathrm{mg} \mathrm{DOC})^{-1} \mathrm{~m}^{-1}, \mathrm{p}>0.56$ ).

The time course of $a 300$ values in the microbial-only incubations followed a similar trend to [DOC]; the percent remaining as compared to the Day 1 a300 values progressively decreased for roughly the first week of the incubation and then plateaued (Fig. 5). Percent $a 300$ remaining plateaued at a higher value than the percent DOC remaining, which indicates that the non-chromophoric was more labile than the chromophoric fraction of the DOC. For some species, $a 300$ increases at the end of the incubation indicating some microbial production of CDOM (Fig. 5).
The UV exposure portion of this experiment was conducted with senescent materials. As a preliminary to comparing the results of the UV + microbial and microbial incubations, we first compare results of the dark (microbial-only) control for the UV + microbial experiment to senescent results of the microbial-only incubations. Figure 6 compares the primary microbial-only incubation with the dark control incubation by displaying percent $a 300$ and DOC remaining at Days 8, 14, and 15. While the microbial incubation and dark control of the UV + microbial incubation saw different rates of degradation (Day 8 values are higher in some of the microbial incubations), the overall change is similar by Days 14 and 15. Differences between the primary microbial incubation (Day 14) and the dark control (Day 15) were not significant, $p>0.05$ in paired comparison t-tests for all species except $S$. pumilus $p=0.035$ which does not meet the Bonferroni-Holm adjusted alpha $=0.01$. Full results from the dark control are available in the Supplementary Material (S1). These results indicate that there was little effect of volume or filter presence on the ultimate effect of microbial degradation.

The UV + microbial incubation was irradiated for 8 days, then kept in the dark for another week. This approach was used to test the hypothesis that prior photodegradation enhances subsequent microbial degradation. As far as $\% \mathrm{BDOC}$, this hypothesis was not supported as there was no
Fig. 5 Percentage of DOC remaining in solution and percentage of $a 300$ remaining over the course of the 15- and 42-day incubations for a I. frutescens leaf, b $P$. australis leaf, c $S$. americanus, $\mathbf{d} S$. pumilus, and $\mathbf{e}$ T. angustifolia leaf. Solid lines represent percent remaining DOC, whereas dashed lines represent percent remaining a300. Circles represent the microbial-only senescent cutting extract data, squares represent $\mathrm{UV}+$ microbial incubation, and error bars are standard deviation. Each point represents an average of triplicates
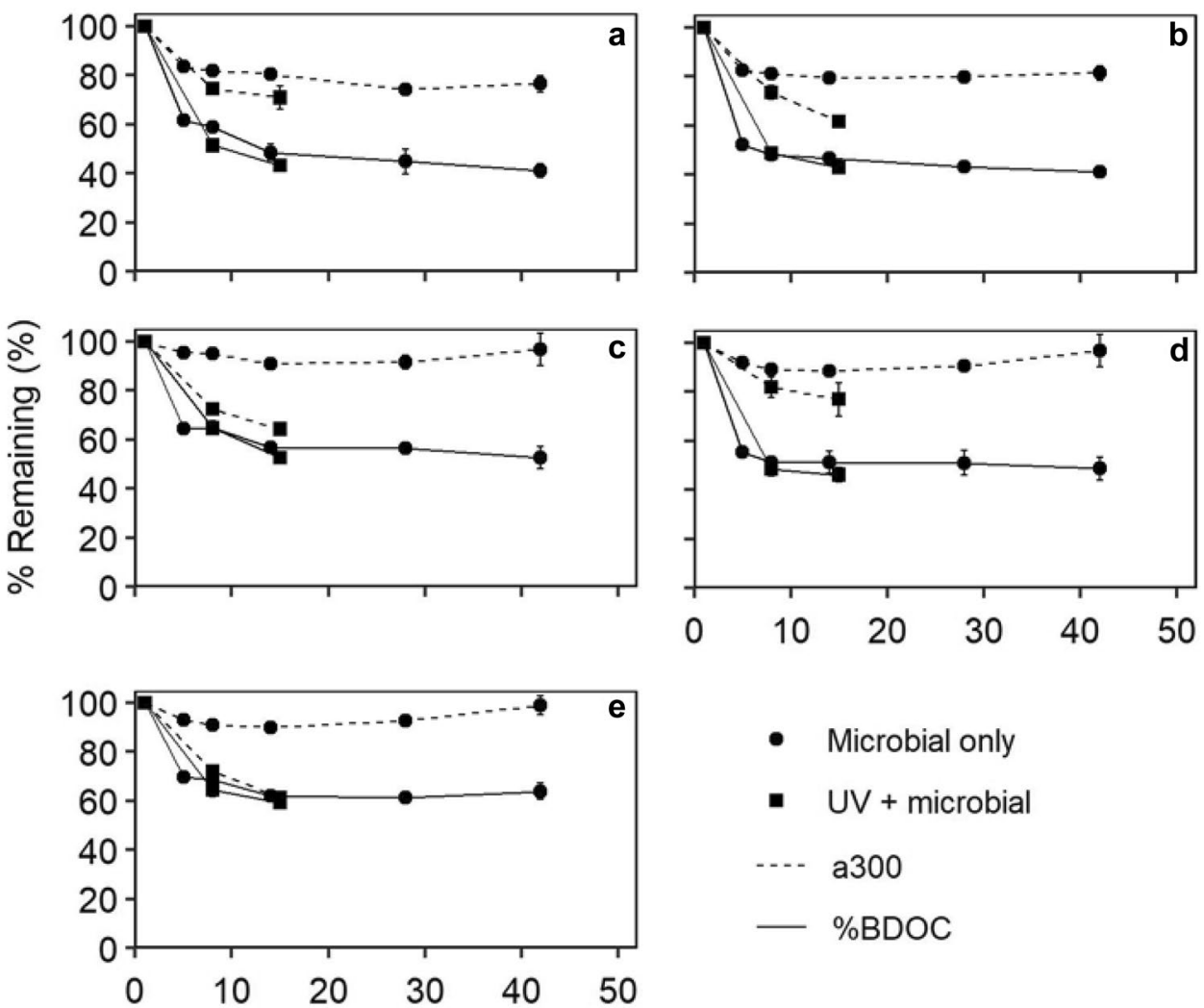

- Microbial only

- UV + microbial

-.. a300

- \%BDOC

Duration of Incubation (d) 
Fig. 6 Comparison of the senescent microbial incubation and the dark control of the $\mathrm{UV}+$ microbial incubation, representing the average of triplicate incubations. a Percent DOC remaining at Day 8 and Day 14, for the microbial incubation, and Day 15, the final day of the UV incubation. b Percent absorbance remaining at Day 8 and Days 14 and 15. Dark grey represents the microbial incubation, and light grey represents the dark control for the UV exposed incubation. Unbolded is the Day 8 data, while bolded is the Days 14 and 15 data. Error bars represent standard deviation. In some cases, error bars are smaller than border width
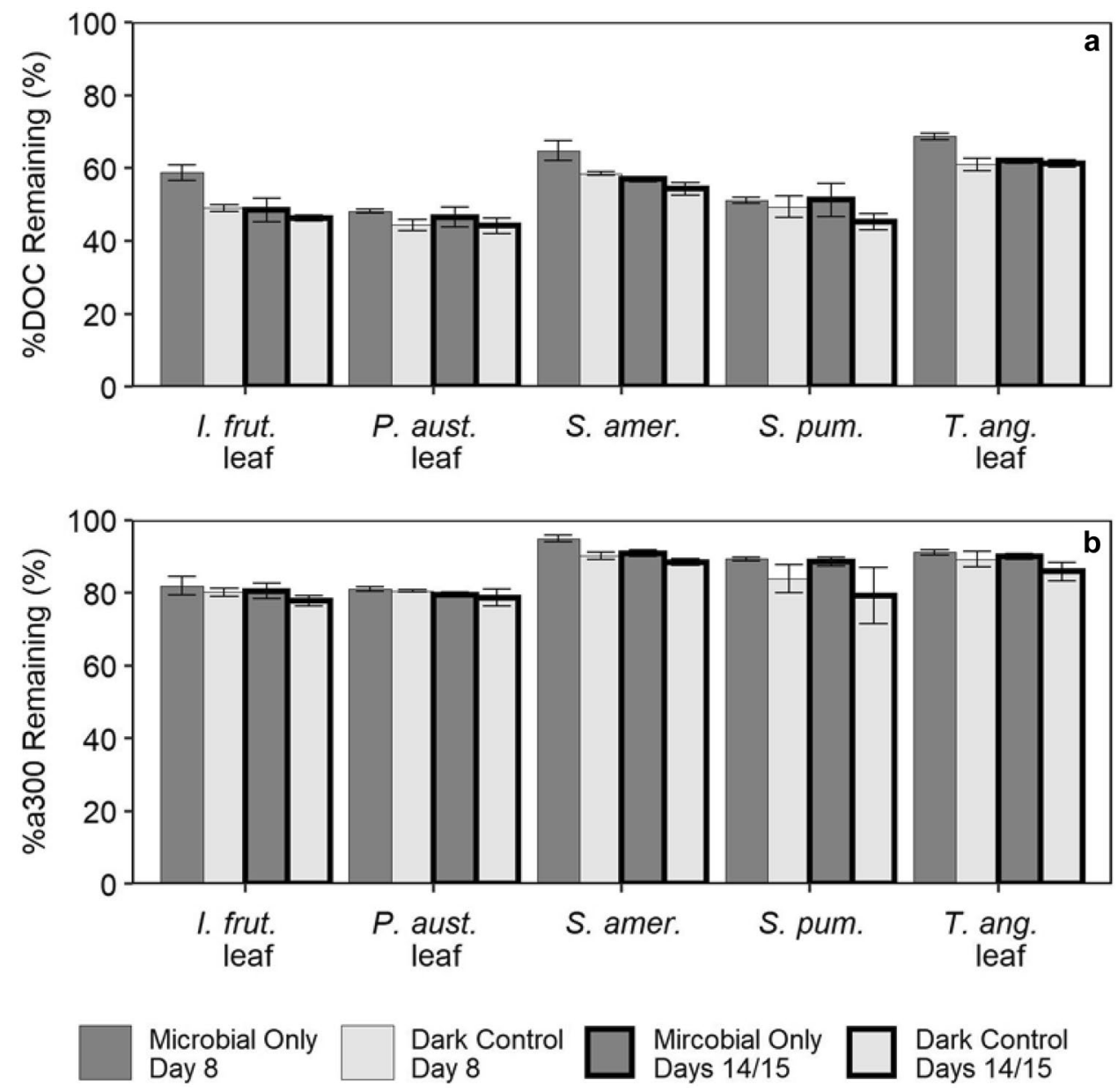

consistent difference in the percent DOC remaining between the UV + microbial exposed on Day 15 and microbial incubations at Day 14 (Fig. 5). However, a300 remaining for the $\mathrm{UV}+$ microbial incubations $(74.9 \pm 4.57 \%)$ are consistently lower than the values for the regular senescent dark incubation $(87.7 \pm 5.70 \%, p<0.0001)$ at Day 8 , indicating that CDOM in the leachates was photobleached (Fig. 5). Absorbance in the UV + microbial incubations continued to decrease during the second week of dark incubation following UV exposure $(67.0 \pm 7.35 \%$ for $U V+$ microbial incubation and $86.0 \pm 5.23 \%$ for senescent incubation at Days 14 and 15, $p<0.0001)$. During the same period, there was little change in absorbance in the microbial-only incubation. This demonstrates that UV exposure mediates CDOM degradation not only by photobleaching but also by enhancing subsequent microbial degradation of CDOM.

While there is no consistent trend, SUVA280 values generally did increase over time during the fresh, senescent, and UV + microbial incubations (Fig. 7). This trend results from the greater decrease in DOC than absorbance during the incubations (cf. Figure 5). The change in SUVA280 does vary significantly between the fresh and senescent material $(p=0.0016)$. In addition, the senescent material microbial-only incubation saw a significantly greater increase in SUVA280 than the UV exposed incubation $(p<0.0001)$ during which absorbance decreased due to photobleaching.

\section{Changes in Marsh Plant CDOM Fluorescence Signature}

Synchronous fluorescence, fluorescence indices and EEMs of the plant leachates were measured; however, only the EEMs are presented this report. The other measurements are included in the supplemental information (Table S1). A PARAFAC analysis was completed using the whole EEMs data set $(n=137)$. A four-component model was fit and passed the split validation procedure as conducted by the drEEM toolbox (Tucker Congruence Coefficient $>0.95$, for all six paired comparisons). A single PARAFAC model was fit for the whole data set so that we could directly compare scores for fresh and senescent material from the same species. After being compared with the OpenFluor database (Murphy et al. 2014), each component was assigned an identity (Fig. 8; Table 3). The three best fitting models are listed for each component, with decreasing 


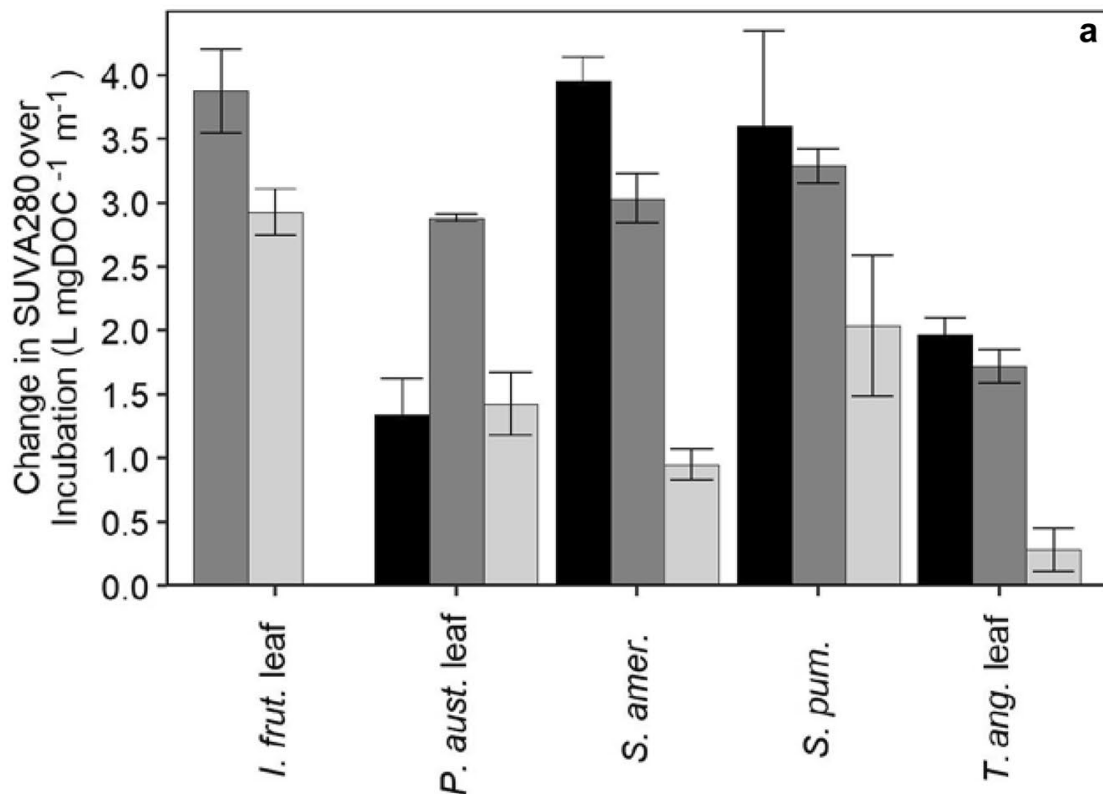

Microbial Only Fresh
Microbial Only Senescent

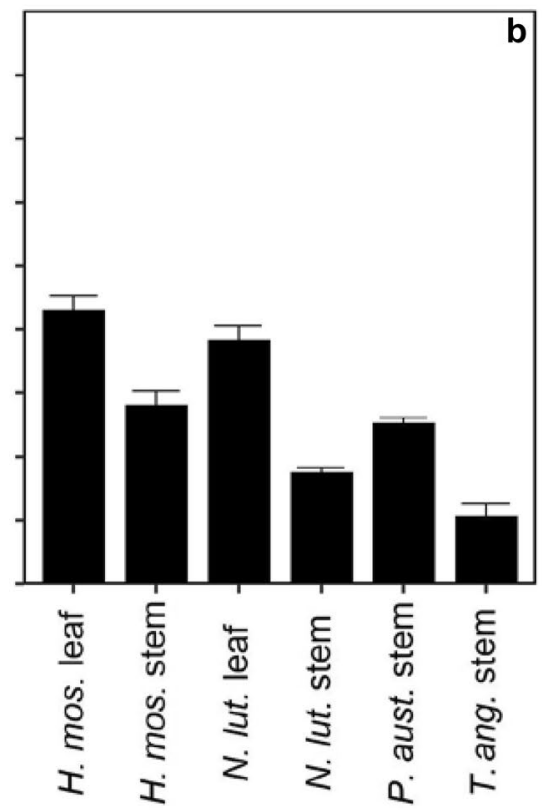

UV + Microbial Senescent
Fig. 7 Change in SUVA280 over the incubations for a species where only senescent material (Iva frutescens) or both fresh and senescent material were incubated and $\mathbf{b}$ for species where only fresh material was incubated. Black represents the change for the incubated fresh material (56 days), dark grey represents the change for the incubated

Tucker's Congruence Coefficient. Component 1 (C1) is "UV humic"(Walker et al. 2013; Søndergaard et al. 2003; Murphy et al. 2008). Component 2 (C2) is "protein-like" or "tryptophan-like" fluorescence (Cawley et al. 2012; Yamashita et al. 2010b, 2010a) indicative of intact proteins or less degraded peptide material (Fellman et al. 2010). Component 3 (C3) is "Vis humic" (Yamashita et al. 2011; Garcia et al. 2015; Peleato et al. 2017). Component 4 (C4) is "protein-like," similar to "tyrosine-like" fluorescence (D'Andrilli et al. 2019; Chen et al. 2018; Kowalczuk et al. 2013) and indicative of more degraded peptide material (Fellman et al. 2010). Broader nomenclature within the OpenFluor database typically classifies humics as terrestrial or marine. Since this is not a relevant classification for plant leachates, we used here the nomenclature in Logozzo et al. (2021), in which marine humics are "UV humic" and terrestrial humics are "Visible humic." For the fresh material extracts, $\mathrm{C} 2$ makes up the largest percent contribution to the PARAFAC components at Day $1(37.5 \pm 13.7 \%)$, followed by $\mathrm{C} 1(34.4 \pm 11.6 \%), \mathrm{C} 4(22.4 \pm 15.4 \%)$, and C3 $(5.71 \pm 9.0 \%)$, with the smallest percent contribution. For the senescent material extracts, $\mathrm{C} 1$ has the greatest percent contribution on average $(45.1 \pm 11.4 \%)$, followed by C2 $(29.9 \pm 6.7 \%), \mathrm{C} 3(13.8 \pm 1.7 \%)$, and C4 (11.1 $\pm 5.8 \%)$, with the smallest percent contribution. Thus, the senescent senescent material (42 days), and light grey represents the change for the UV exposed material (15 days). The change in SUVA280 was calculated for each incubation individually; the graph represents the average of triplicate incubations, and error bars are the standard deviation

material extracts have a greater contribution of the humic components.

Normalized to DOC concentration (i.e., component score divided by DOC concentration) and compared to fresh material, the senescent material extract had
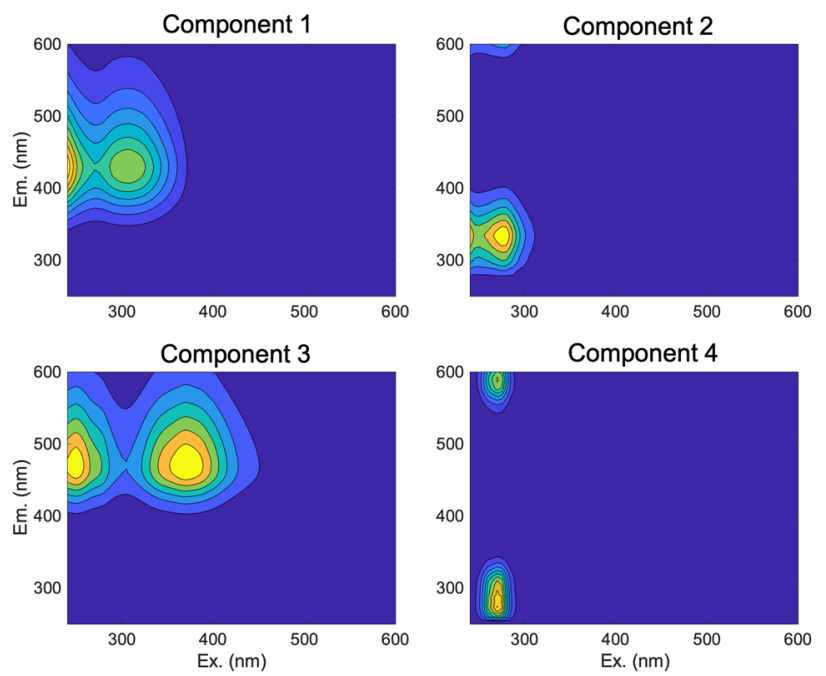

Fig. 8 Excitation/emission maps of each component from the PARAFAC Analysis 
Table 3 Identification of each fluorescence component isolated through PARAFAC analysis using the OpenFluor database (Murphy et al. 2014)

\begin{tabular}{lllll}
\hline Component & Excitation Max $(\mathrm{nm})$ & $\begin{array}{l}\text { Emission Max } \\
(\mathrm{nm})\end{array}$ & Identification & \\
\hline 1 & $<250,305$ & 430 & UV Humic & Walker et al. (2013) \\
2 & 275 & 334 & protein-like & Cawley et al. (2012) \\
3 & 250,370 & 470 & Vis Humic & Yamashita et al. (2011) \\
4 & 270 & 274 & protein-like & D'Andrilli et al. (2019) \\
\hline
\end{tabular}

significantly greater component values at Day 1 for $\mathrm{C} 1$ (normalized score of $0.0323 \pm 0.0248$ for fresh material and $0.101 \pm 0.0314$ for senescent material; $p=0.0004$ ), C2 (normalized score of $0.0287 \pm 0.0133$ for fresh material and $0.0674 \pm 0.0174$ for senescent material; $p=0.0004)$, and C3 (normalized score of $0.00356 \pm 0.00485$ for fresh material and $0.0314 \pm 0.00709$ for senescent material; $p=0.0006)$. C4 did not vary significantly between fresh and senescent material (normalized scores of $0.0194 \pm 0.0196$ and $0.0245 \pm 0.0129$, respectively; $p=0.221$, (Kruskal-Wallis Test)).

For the fresh, senescent, and UV + microbial extract incubations, $\mathrm{C} 1$ and $\mathrm{C} 2$ consistently decreased, while $\mathrm{C} 3$ and $\mathrm{C} 4$ were more variable (Fig. 9). This indicates that protein-like (tryptophan-like) and UV humic material tended to be more labile. While $\mathrm{C} 2$ was the most labile component, on average, for the microbial-only incubations (Fig. 9b), exposure to UV light dramatically increased the loss of $\mathrm{C} 1$ (Fig. 9c). When comparing the general percent loss of components over the incubation, we focused on $\mathrm{C} 1$ and $\mathrm{C} 2$ as they consistently decreased and made up the largest percent contribution. In Fig. 9d, we display the percent loss of $\mathrm{C} 1$ and $\mathrm{C} 2$ and \%BDOC averaged among the incubation types (fresh material extract, senescent material extract, and UV exposed); $\mathrm{C} 1$ clearly decreases the most for the $\mathrm{UV}+$ microbial incubation while $\mathrm{C} 2$ tracks more closely to \%BDOC.

Given that previous studies reported correlations between leachate fluorescence components and biodegradability (e.g., Pinsonneault et al. 2016), we examined the relationship between fluorescence components normalized to (DOC) at Day 1 and the \%BDOC in both fresh and senescent microbial-only incubations as well as UV + microbial and dark control incubations (Fig. 10). \%BDOC was not substantially different for the UV + microbial incubations compared to the microbial-only senescent incubations, and \%BDOC at Day 15 approximates the final \%BDOC value for the senescent data. Out of all of the components, the humic components, $\mathrm{C} 1$ and $\mathrm{C} 3$, show the strongest relationship with \% BDOC with an inverse correlation. There is also a clear distinction between the fresh material and senescent material in the DOC-specific content of both $\mathrm{C} 1$ and $\mathrm{C} 3$ as well as in $\%$ BDOC.

\section{Discussion}

This study highlights key patterns in the biodegradation and photodegradation of DOM in leachates from Chesapeake Bay wetland plants. Two of our three initial hypotheses were supported. We found that senescent material leached more DOM than fresh material, in accordance with the "fall dump" hypothesis, and that DOM became more refractory in all incubations throughout the degradation process. However, the UV + microbial exposed material did not become more labile as we had hypothesized, even though $\mathrm{UV}+$ microbial exposure did impact CDOM absorbance and which fluorescence components were transformed compared to microbial exposure alone. Additional key takeaways include the following: there are clear differences between the fresh and senescent plant material in character of DOM extracts, and \%BDOC in marsh plant leachates is greater than previously observed in bulk DOM exported at low tide (cf. Logozzo et al. 2021).

\section{Amount and Characteristics of DOM in Leachates from Marsh Plants}

As $[\mathrm{DOC}]_{0}$ for the senescent material was significantly greater than $[\mathrm{DOC}]_{0}$ for the fresh material for all compared species, our study supports the fall dump hypothesis, in which more DOC is leached during the senescent period of plants in the fall (Qi et al. 2017; Schiebel et al. 2018). Tzortziou et al. (2008), Osburn et al. (2015), and Logozzo et al. (2021) found that DOM concentrations in water draining tidal marshes peaked during the late summer-early fall (i.e., July to September in Tzortziou et al. 2008). Altogether, these studies show that several factors impact export of DOC from tidal marshes including DOC leaching, precipitation, and degradation of organic material.

While Pinsonneault et al. (2016) focuses on a cool temperate bog instead of a tidal marsh ecosystem, their results still serve as an interesting comparison given how closely the methodologies align. Pinsonneault et al. (2016) found that fresh cuttings had greater $[\mathrm{DOC}]_{0}$ than peat and litter extracts. However, they collected plant litter in traps on the bog surface, in which the litter would have been subject to surface conditions, and thus potential transformation, for days to weeks, while in our study, senescent material was directly collected 

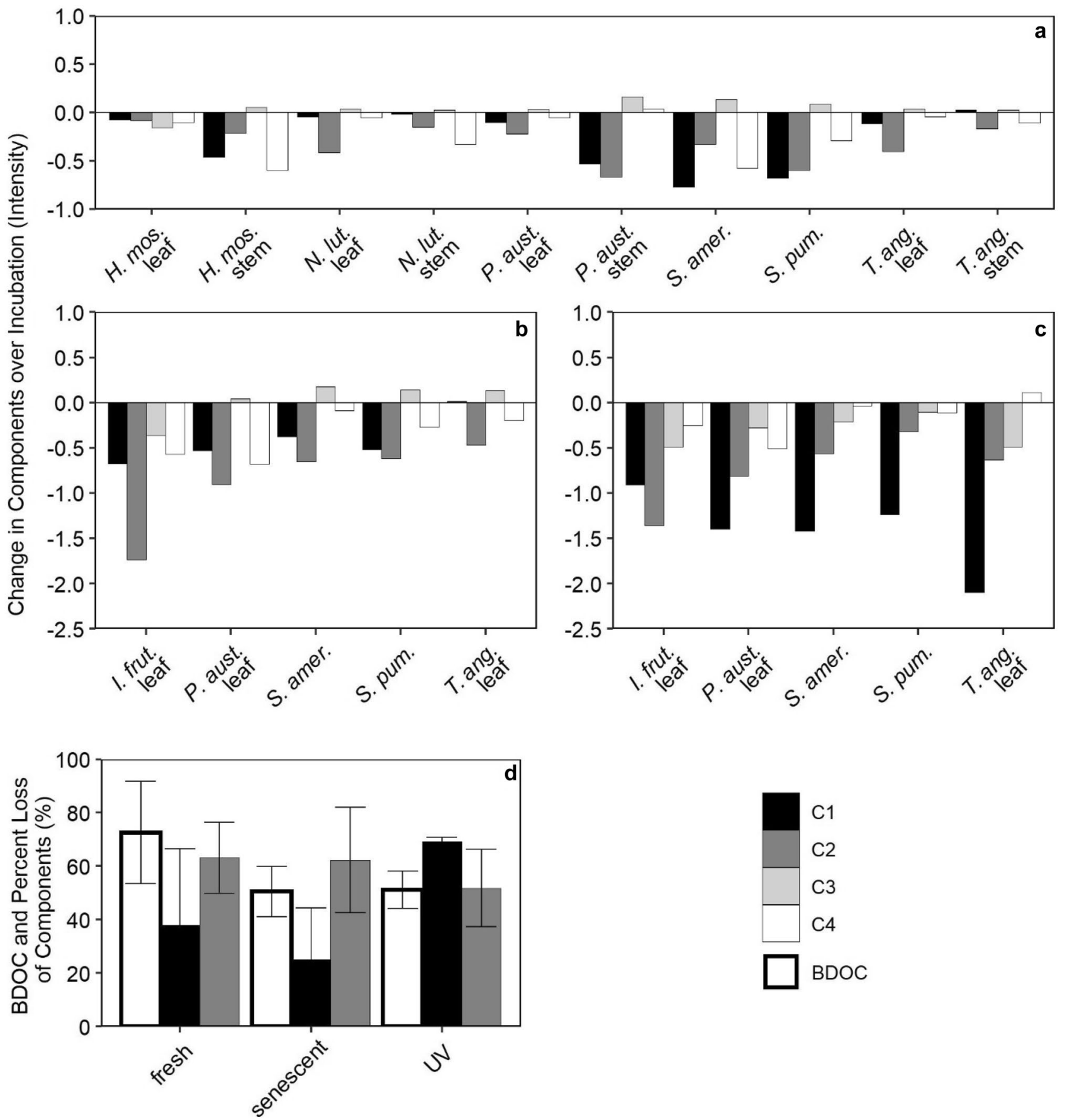

Fig. 9 Change in scores of PARAFAC components over the duration of the incubations for a the 56-day incubation using fresh material extracts, b the 42-day incubation using senescent material extracts, and $\mathbf{c}$ the UV + microbial 14 day incubation; no error is provided as values were derived from the PARAFAC model. d demonstrates the average \%BDOC and average percent loss of Components 1 and 2

from the marsh plants. Similar to Pinsonneault et al. (2016), which found that SUVA254 was greater in litter extracts than fresh material extracts, SUVA280 was significantly greater in the senescent material extracts, indicating that these extracts

over the incubation for the fresh, senescent, and UV + microbial incubations; error is standard deviation. Black represents $\mathrm{C} 1$, dark grey represents $\mathrm{C} 2$, light grey represents $\mathrm{C} 3$, white represents $\mathrm{C} 4$, and bolded white represents BDOC. Note in panel $\mathbf{d}$ that only BDOC, $\mathrm{C} 1$, and $\mathrm{C} 2$ are depicted

had a greater contribution of aromatic material. While SUVA280 and SUVA254 use different wavelengths, both are a measure of the aromatic content of CDOM (Chin et al. 1994; Weishaar et al. 2003; Hansen et al. 2016). 

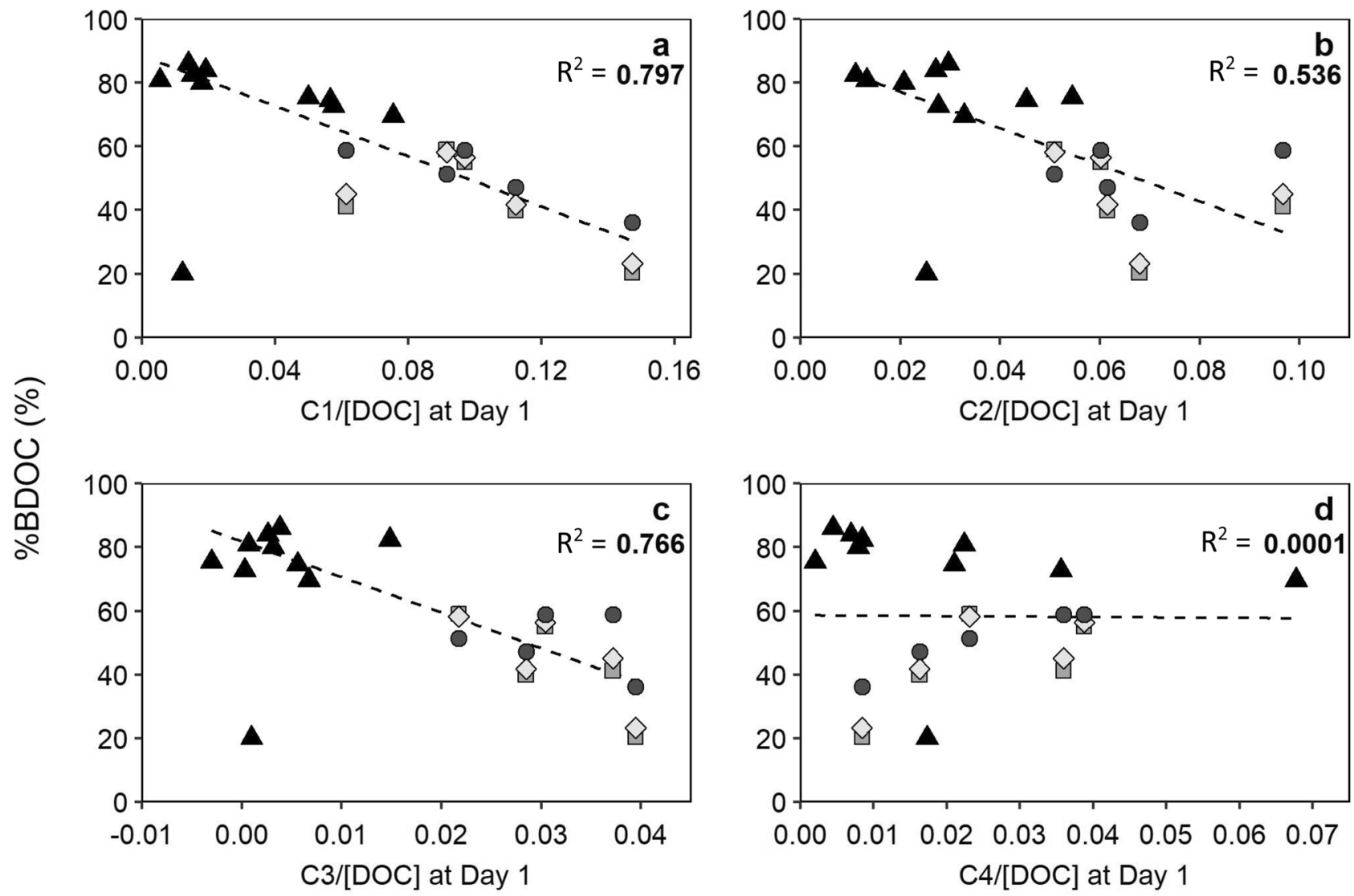

Fresh Microbial-only

\section{Dark Control $\diamond$ UV+microbial}

Fig. $10 \%$ BDOC compared to PARAFAC component scores normalized to [DOC] at Day 1, where $\mathbf{a}$ is Component $1, \mathbf{b}$ is Component 2, $\mathbf{c}$ is Component 3, and $\mathbf{d}$ is Component 4 . Triangles represent the fresh incubation (Day 56), circles represent the senescent microbial-

Within the fresh material, all of the different species had similar $[\mathrm{DOC}]_{0}$ and \%BDOC. Also, \%BDOC did not differ substantially between leaf and stem extracts, except for Typha. Thus, species diversity within marshes may not have a substantial impact on DOC concentrations or BDOC during the growing season. In contrast, the $[\mathrm{DOC}]_{0}$ of senescent material did vary between species, indicating that during the senescence season, marsh plant species composition can impact DOC stocks in the system. The significant variability in SUVA280 across all species suggests that differences in marsh plant species composition would impact the molecular weight and aromaticity of DOC leaching to the system. DOM in different molecular weight size fractions has been shown to support different microbial communities (Covert and Moran, 2001) and is utilized in different amounts with varying amounts of bacterial growth and respiration (Kaplan and Bott 1983; Meyer et al. 1987; Amon and Benner 1994, 1996; Hopkinson et al. 1998), and thus a change in DOM only incubation (Day 42), squares represent the dark control incubation (Day 15), and diamonds represent the UV + microbial incubation (Day 15). The fresh T. angustifolia stem was excluded from the linear regression as it is an outlier, and the number displayed is R-squared

composition due to a change in predominant plant species may cause changes in aquatic microbial communities. However, the level of DOM degradation may also be a key factor in what microbial communities are supported (Hopkinson et al. 1998).

We found that the senescent material has a larger contribution of humic components as a percent of the total or per unit DOC compared to fresh leachate. The prominence of the protein-like component $\mathrm{C} 2$ in the leachates distinguishes the leachate CDOM from CDOM collected from water draining these tidal marshes, in which the contribution of protein-like component is typically small (Logozzo et al. 2021). In addition to $C 2$, the leachates had a secondary, less labile, protein-like component, $\mathrm{C} 4$, with a similar spectral signature to the protein-like component found in tidal marsh surface water (Logozzo et al. 2021). The shorter wavelength fluorescence emission (304-312 nm) of $\mathrm{C} 4$ is similar to "tyrosine-like" fluorescence and thus is most likely associated with more degraded, and less 
bioavailable, material (Fellman et al. 2010; Hotchkiss et al. 2014; Pinsonneault et al. 2016). The Pinsonneault et al. (2016) peat study similarly had a minor protein-like component; however, they also found a greater percent contribution of protein-like components in the fresh material, which drove a positive relationship between percent protein-like material and BDOC.

\section{Bioavailability of Marsh Plant DOM}

Compared to the bulk DOM (derived from plants and soil) exported from marshes at low tide (Logozzo et al. 2021), the fresh and senescent plant leachate incubations exhibited a much larger \%BDOC. Bulk DOM exported from marshes in the Chesapeake Bay including Kirkpatrick Marsh and Jug Bay wetlands averaged 5.5\% BDOC in a 14 day microbialonly incubation (Logozzo et al. 2021), while in our study, most microbial-only incubations exhibited a \%BDOC greater than $50 \%$ by Day 14 .

Although DOM from senescent marsh plant material had higher initial [DOC], it was consistently characterized by lower bioavailability than DOM in fresh plant leachate, suggesting previous degradation in the field. Fellman et al. (2013) similarly found that \%BDOC decreased with litter age, but total BDOC was independent of litter age, and in Pinsonneault et al. (2016), the fresh material extract had a higher \%BDOC than the peat and litter extracts. Wiegner and Seitzinger (2004) found that DOC had the greatest bioavailability in the spring, which they attributed to freeze/thaw cycles. Similar to our results, Wang et al. (2014) found that senescent material tended to have a lower \%BDOC than the fresh material and also found greater degradation rates towards the beginning of the incubation.

Along with other studies (Hansen et al. 2016; Pinsonneault et al. 2016), our SUVA280 values (a proxy for molecular weight and aromaticity) increased throughout the incubation, suggesting that by the end of the incubation high molecular weight, more aromatic compounds constitute a larger fraction of DOM. This is consistent with the observed increase in relative contribution of longer wavelength absorbance.

Conversely, increases in SUVA280 indicate the preferential degradation of non-chromophoric material. This is also shown in the time courses of the microbial-only incubations, in which there was a relatively small percent loss of absorbance at $300 \mathrm{~nm}$ compared to percent loss of DOC (Fig. 5). In some species the loss was followed by a small gain in absorbance suggesting microbial production of CDOM and/ or transformation of non-chromophoric to chromophoric DOM as has been reported for estuarine DOM (Logozzo et al. 2021).

\section{Impacts of UV Exposure on Bioavailability of Marsh Plant DOM}

The UV + microbial incubation tracked relatively closely to the DOC degradation patterns found in the microbial-only incubation of the senescent material (Fig. 5). This suggests that UV exposure has little effect on the microbial lability of DOC in plant leachates, but this should be examined further using increased intensity or longer exposure times. Exposure duration and intensity in the present experiment were limited by container size and lamp output, and were considerably lower than other studies that found that UV exposure of DOC from streams and tidal marsh surface water increased overall lability to microbial degradation (Moran et al. 2000; Vähätalo and Wetzel 2008; Lu et al. 2013; Logozzo et al. 2021). Fellman et al. (2013) also did not observe any significant change in \%BDOC with UV exposure (using a UV-B bandwidth lamp) for fresh and 2 month old leaf litter, even though they saw an increase in \%BDOC in 4 and 6 month old litter.

While there was not a clear difference in DOC remaining between the UV + microbial incubation at Day 15 and the microbial-only incubation at Day 14, the UV + microbial incubation had a significantly larger decrease in $a 300$; thus, photodegradation was the dominant process transforming CDOM. Component 1 of the PARAFAC analysis also had a larger decrease in comparison to the senescent microbial-only incubation, further suggesting that photobleaching plays an important role in DOM transformation during the combined microbial-photodegradation incubations (Logozzo et al. 2021). In addition, $a 300$ in the UV + microbial incubation continued to decrease between Days 7 and 15 even though the microbial incubation had almost no change, which suggests that the photoexposure did make the material more labile (as compared to the microbial-only senescent incubation) to microbially mediated changes that affected absorbance and fluorescence while DOC concentrations remained largely the same. This could indicate that the molecular weight was decreasing (Helms et al. 2008).

A substantial loss of most of the fluorescent components was found during all incubations of DOM from marsh plant leachates, in both microbial and UV + microbial incubations. Logozzo et al. (2021) found that microbial processing resulted in minor changes $(< \pm 10 \%)$ in the fluorescence components in bulk (i.e., derived from marsh plants and soil) DOM exported from tidal marshes at low tide, with small increases for material from Kirkpatrick marsh while most fluorescent components decreased in bulk DOM exported from the Jug Bay marshes. Increases of $>10 \%$ occurred in material pre-exposed to UV for both Kirkpatrick and Jug Bay marshes. Rather than microbial production of fluorescence components from marsh-exported DOM, which could 
be by transformation of non-chromophoric to chromophoric organic matter (Rochelle-Newall and Fisher 2002), our results for marsh plant leachates indicate an overall decrease in all fluorescent components.

Given the inverse relationship between \%BDOC and DOC-normalized fluorescence components, a lower content of fluorescent material in the plant leachates is associated with greater long-term biodegradability. The inverse correlation between the content of humic components $(\mathrm{C} 1$ and $\mathrm{C} 3$ ) and \%BDOC and distinction between fresh and senescent material (Fig. 10) demonstrates that DOM with a higher fraction of humic components tends to have a lower $\% \mathrm{BDOC}$, and that extracts from senescent material tend to be more humic. Thus, it is suggested that humic material is less labile. Supporting this idea, multiple studies have found that protein-like components are preferentially and rapidly degraded (Wickland et al. 2007; Wang et al. 2014; Qi et al. 2017). As a result, the labile protein-like component we observed in marsh plant leachates is expected to be considerably degraded (and thus in very small amounts) in water draining the marshes. Given enough time, photochemical and microbial processing can synergistically completely mineralize at least some forms of wetland derived DOM (Vähätalo and Wetzel 2008), with our incubations suggesting that UV exposure enhances the microbial degradation of the UV-humic fluorescent component in marsh plant leachates.

\section{Conclusion}

Ultimately, there were distinctions between the leachates sourced from fresh and senescent dissolved organic material, and UV exposure impacted how degradation occurred. The senescent material leached a greater concentration of DOC and a greater total of biodegradable DOC despite having a smaller, more labile, fraction of BDOC. The senescent material also had greater high molecular weight contributions. Due to these distinctions between the fresh and senescent material, DOM quality and quantity may also shift seasonally as climate change impacts some triggers of senescence, such as autumn temperatures, drought, and frost events. However, some species may not be as susceptible to climactic changes as the timing of their senescence depends on photoperiod (Gallinat et al. 2015).

The senescent material had a greater contribution of humiclike components, which were less degradable than the protein-like components. Even though it did not affect \%BDOC, $\mathrm{UV}+$ microbial incubations did increase the degradability of the humic-like components. These findings demonstrate that UV exposure does impact the degradation of leachate DOM differently than microbes. When comparing between species, changes in marsh plant species composition can lead to changes in DOM composition and degradation of released leachates, even if the DOC concentration is relatively similar. Quantifying the impact of anthropogenic disturbances, climate change, and environmental conditions on vegetation characteristics and biodiversity in tidal wetlands is, thus, key in further understanding the role of these systems in coastal carbon budgets and cycles.

Supplementary Information The online version contains supplementary material available at https://doi.org/10.1007/s12237-021-00982-7.

Acknowledgements We would like to thank Danchau (Claudia) Nguyen for assistance with a large portion of the laboratory work and Patrick Megonigal for assistance with the development of this project. We would also like to thank Andrew Peresta for laboratory assistance. We thank the reviewers for their thorough reading of the mss and many suggestions to help improve readability and clarity.

Funding Funding for the project came from National Science Foundation (NSF) Grant DEB-1556556. Sydney Shelton was supported by a NSF Research Experiences for Undergraduates (REU) supplemental award and the REU site grant to the Smithsonian Environmental Research Center.

Open Access This article is licensed under a Creative Commons Attribution 4.0 International License, which permits use, sharing, adaptation, distribution and reproduction in any medium or format, as long as you give appropriate credit to the original author(s) and the source, provide a link to the Creative Commons licence, and indicate if changes were made. The images or other third party material in this article are included in the article's Creative Commons licence, unless indicated otherwise in a credit line to the material. If material is not included in the article's Creative Commons licence and your intended use is not permitted by statutory regulation or exceeds the permitted use, you will need to obtain permission directly from the copyright holder. To view a copy of this licence, visit http://creativecommons.org/licenses/by/4.0/.

\section{References}

Amon, Rainer M. W., and Ronald Benner. 1994. Rapid cycling of highmolecular-weight dissolved organic matter in the ocean. Nature 369: 549-552. https://doi.org/10.1038/369549a0.

Amon, Rainer M. W., and Ronald Benner. 1996. Bacterial utilization of different size classes of dissolved organic matter. Limnology and Oceanography 41: 41-51. https://doi.org/10.4319/lo.1996. 41.1.0041.

Balogh, Katalin V., Mátyás Présing, Lajos Vörös, and Noémi Tóth. 2006. A study of the decomposition of reed (Phragmites australis) as a possible source of aquatic humic substances by measuring the natural abundance of stable carbon isotopes. International Review of Hydrobiology 91: 15-28. https://doi.org/10.1002/iroh. 200510820.

Cawley, Kaelin M., Kenna D. Butler, George R. Aiken, Laurel G. Larsen, Thomas G. Huntington, and Diane M. McKnight. 2012. Identifying fluorescent pulp mill effluent in the Gulf of Maine and its watershed. Marine Pollution Bulletin 64: 1678-1687. https:// doi.org/10.1016/j.marpolbul.2012.05.040.

Cestti, Rita, Jitendra Srivastava, and Samira Jung. 2003. Agriculture non-point source pollution control: Good management practicesThe Chesapeake Bay experience. World Bank Working Paper 7. https://doi.org/10.1596/0-8213-5523-6. 
Chen, Meilian, Jinyoung Jung, Yun Kyung Lee, and Jin Hur. 2018. Surface accumulation of low molecular weight dissolved organic matter in surface waters and horizontal off-shelf spreading of nutrients and humic-like fluorescence in the Chukchi Sea of the Arctic Ocean. Science of the Total Environment 639: 624-632. https://doi.org/10.1016/j.scitotenv.2018.05.205.

Chin, Yu-Ping, George Aiken, and Edward O'Loughlin. 1994. Molecular weight, polydispersity, and spectroscopic properties of aquatic humic substances. Environmental Science \& Technology 28: 1853-1858. https://doi.org/10.1021/es00060a015.

Clark, J. B., W. Long, and R. R. Hood. 2020. A comprehensive estuarine dissolved organic carbon budget using an enhanced biogeochemical model. Journal of Geophysical Research: Biogeosciences 125: e2019JG005442. https://doi.org/10.1029/ 2019JG005442.

Covert, J., and M. Moran. 2001. Molecular characterization of estuarine bacterial communities that use high- and low-molecular weight fractions of dissolved organic carbon. Aquatic Microbial Ecology 25: 127-139. https://doi.org/10.3354/ame025127.

Curtis, P.S., B.G. Drake, P.W. Leadley, W.J. Arp, and D.F. Whigham. 1989. Growth and senescence in plant communities exposed to elevated $\mathrm{CO}_{2}$ concentrations on an estuarine marsh. Oecologia 78: 20-26. https://doi.org/10.1007/BF00377193.

D’Andrilli, Juliana, James R. Junker, Heidi J. Smith, Eric A. Scholl, and Christine M. Foreman. 2019. DOM composition alters ecosystem function during microbial processing of isolated sources. Biogeochemistry 142: 281-298. https://doi.org/10. 1007/s10533-018-00534-5.

Fellman, Jason B., Eran Hood, and Robert G. M. Spencer. 2010. Fluorescence spectroscopy opens new windows into dissolved organic matter dynamics in freshwater ecosystems: A review. Limnology and Oceanography 55: 2452-2462. https://doi.org/ 10.4319/1o.2010.55.6.2452.

Fellman, J.B., K.C. Petrone, and P.F. Grierson. 2013. Leaf litter age, chemical quality, and photodegradation control the fate of leachate dissolved organic matter in a dryland river. Journal of Arid Environments 89: 30-37. https://doi.org/10.1016/j.jaridenv. 2012.10.011.

Fischer, Helmut, Cecilia Mille-Lindblom, Elke Zwirnmann, and Lars J. Tranvik. 2006. Contribution of fungi and bacteria to the formation of dissolved organic carbon from decaying common reed (Phragmites australis). Archiv Für Hydrobiologie 166: 79-97. https://doi.org/10.1127/0003-9136/2006/0166-0079.

Gallinat, Amanda S., Richard B. Primack, and David L. Wagner. 2015. Autumn, the neglected season in climate change research. Trends on Ecology and Evolution 30 (3): 169-176. https://doi. org/10.1016/j.tree.2015.01.004.

Garcia, Roberto D., Mariana Reissig, Claudia P. Queimaliños, Patricia E. Garcia, and Maria C. Dieguez. 2015. Climate-driven terrestrial inputs in ultraoligotrophic mountain streams of Andean Patagonia revealed through chromophoric and fluorescent dissolved organic matter. Science of the Total Environment 521-522: 280-292. https://doi.org/10.1016/j.scitotenv.2015.03.102.

Hansell, Dennis A., and Craig A. Carlson, eds. 2015. Biogeochemistry of marine dissolved organic matter, 2 nd ed. Amsterdam: Elsevier. https://doi.org/10.1016/C2012-0-02714-7.

Hansen, Angela M., Tamara E. C. Kraus, Brian A. Pellerin, Jacob A. Fleck, Bryan D. Downing, and Brian A. Bergamaschi. 2016. Optical properties of dissolved organic matter (DOM): Effects of biological and photolytic degradation. Limnology and Oceanography 61: 1015-1032. https://doi.org/10.1002/lno.10270.

Hedges, John I. 1992. Global biogeochemical cycles: Progress and problems. Marine Chemistry 39: 67-93. https://doi.org/10.1016/ 0304-4203(92)90096-S.

Helms, John R., Aron Stubbins, Jason D. Ritchie, Elizabeth C. Minor, David J. Kieber, and Kenneth Mopper. 2008. Absorption spectral slopes and slope ratios as indicators of molecular weight, source, and photobleaching of chromophoric dissolved organic matter. Limnology and Oceanography 53: 955-969. https://doi.org/10.4319/1o.2008.53.3.0955.

Holm, S. 1979. A simple sequentially rejective multiple test procedure. Scandinavian Journal of Statistics 6 (2): 65-70.

Hopkinson, Charles S., Ishi Buffam, John Hobbie, Joseph Vallino, Michael Perdue, Bruce Eversmeyer, Fredrick Prahl, Joseph Covert, Robert Hodson, Mary Ann Moran, Erik Smith, John Baross, Byron Crump, Stuart Findaly, and Kenneth Foreman. 1998. Terrestrial inputs of organic matter to coastal ecosystems: An intercomparison of chemical characteristics and bioavailability. Biogeoochemistry 43: 211-234. https://doi.org/10. 1023/A:1006016030299.

Hotchkiss, E.R., R.O. Hall, M.A. Baker, E.J. Rosi-Marshall, and J.L. Tank. 2014. Modeling priming effects on microbial consumption of dissolved organic carbon in rivers. Journal of Geophysical Research: Biogeosciences 119: 982-995. https://doi.org/10.1002/ 2013JG002599.

Jordan, Thomas E., and David L. Correll. 1991. Continuous automated sampling of tidal exchanges of nutrients by brackish marshes. Estuarine, Coastal and Shelf Science 32: 527-545. https://doi. org/10.1016/0272-7714(91)90073-K.

Kaplan, Louisa, and Thomas L. Bott. 1983. Microbial heterotrophic utilization of dissolved organic matter in a piedmont stream. Freshwater Biology 13: 363-377. https://doi.org/10.1111/j.1365-2427. 1983.tb00686.x.

Kowalczuk, Piotr, Gavin H. Tilstone, Monika Zabłocka, Rüdiger Röttgers, and Rob Thomas. 2013. Composition of dissolved organic matter along an Atlantic Meridional Transect from fluorescence spectroscopy and Parallel Factor Analysis. Marine Chemistry 157: 170-184. https://doi.org/10.1016/j.marchem.2013.10.004.

Logozzo, Laura, Maria Tzortziou, Patrick Neale, and J. Patrick Megonigal. 2021. Photochemical and microbial degradation of colored dissolved organic matter exported from tidal marshes. Journal of Geophysical Research - Biogeosciences 126: e2020JG005744. https://doi.org/10.1029/2020JG005744

Lu, Yuehan, James E. Bauer, Elizabeth A. Canuel, R.M. Youhei Yamashita, and Chambers, and Rudolf Jaffé. 2013. Photochemical and microbial alteration of dissolved organic matter in temperate headwater streams associated with different land use. Journal of Geophysical Research: Biogeosciences 118: 566-580. https://doi. org/10.1002/jgrg. 20048.

Medeiros, Patricia M., Michael Seidel, Scott M. Gifford, Ford Ballantyne, Thorsten Dittmar, William B. Whitman, and Mary Ann Moran. 2017. Microbially-mediated transformations of estuarine dissolved organic matter. Frontiers in Marine Science 4: 69. https://doi.org/10.3389/ fmars.2017.00069.

Menendez, Alana B. 2017. Temporal variability of fluorescent dissolved organic matter at a brackish, tidal marsh-estuary interface. MSc Thesis, City University of New York, 2017.

Meyer, Judy L., Richard T. Edwards, and Rebecca Risley. 1987. Bacterial growth on dissolved organic carbon from a blackwater river. Microbial Ecology 13: 13-29. https://doi.org/10.1007/BF02014960.

Moran, Mary Ann, Wade M. Sheldon, and Richard G. Zepp. 2000. Carbon loss and optical property changes during long-term photochemical and biological degradation of estuarine dissolved organic matter. Limnology and Oceanography 45: 1254-1264. https://doi.org/10.4319/lo.2000.45.6.1254.

Murphy, Kathleen R., Colin A. Stedmon, T. David Waite, and Gregory M. Ruiz. 2008. Distinguishing between terrestrial and autochthonous organic matter sources in marine environments using fluorescence spectroscopy. Marine Chemistry 108: 40-58. https://doi. org/10.1016/j.marchem.2007.10.003.

Murphy, Kathleen R., Colin A. Stedmon, Daniel Graeber, and Rasmus Bro. 2013. Fluorescence spectroscopy and multi-way techniques. 
PARAFAC. Analytical Methods 5: 6557-6566. https://doi.org/10. 1039/C3AY41160E.

Murphy, Kathleen R., Colin A. Stedmon, Philip Wenig, and Rasmus Bro. 2014. Openfluor- An online spectral library of auto-fluorescence by organic compounds in the environment. Analytical Methods 6: 658-661. https://doi.org/10.1039/C3AY41935E.

Osburn, Christopher L., Molly P. Mikan, J. Randall Etheridge, Michael R. Burchell, and François Birgand. 2015. Seasonal variation in the quality of dissolved and particulate organic matter exchanged between a salt marsh and its adjacent estuary. Journal of Geophysical Research: Biogeosciences 120: 1430-1449. https://doi. org/10.1002/2014JG002897.

Peleato, Nicolás M., Balsher Singh Sidhu, Raymond L. Legge, and Robert C. Andrews. 2017. Investigation of ozone and peroxone impacts on natural organic matter character and biofiltration performance using fluorescence spectroscopy. Chemosphere 172: 225-233. https://doi.org/10.1016/j.chemosphere.2016.12.118.

Pinsonneault, Andrew J., Tim R. Moore, Nigel T. Roulet, and JeanFrançois. Lapierre. 2016. Biodegradability of vegetation-derived dissolved organic carbon in a cool temperate ombrotrophic bog. Ecosystems 19: 1023-1036. https://doi.org/10.1007/ s10021-016-9984-z.

Pinsonneault, Andrew J., Patrick J. Neale, Maria Tzortziou, Elizabeth A. Canuel, Christina R. Pondell, Hannah Morrissette, Jonathan S. Lefcheck, and James Patrick Megonigal. 2020. Dissolved organic carbon sorption dynamics in tidal marsh soils. Limnology and Oceanography 66: 214-225. https://doi.org/10.1002/lno.11598.

Qi, Yuanzhi, Yuejun Xue, and Xuchen Wang. 2017. Release and microbial degradation of dissolved organic carbon and nitrogen from Phragmites australis and Suaeda salsa in the wetland of the Yellow River Estuary. Journal of Oceanography and Marine Research 5: 2. https://doi.org/10.4172/2572-3103.1000160.

Rochelle-Newall, E.J., and T.R. Fisher. 2002. Production of chromophoric dissolved organic matter fluorescence in marine and estuarine environments: An investigation into the role of phytoplankton. Marine Chemistry 77: 7-21. https://doi.org/10.1016/ S0304-4203(01)00072-X.

Schiebel, Hayley N., George B. Gardner, Xuchen Wang, Francesco Peri, and Robert F. Chen. 2018. Seasonal export of dissolved organic matter from a New England salt marsh. Journal of Coastal Research 344: 939-954. https://doi.org/10.2112/JCOASTRES-D-16-00196.1.

Søndergaard, Morten, Colin A. Stedmon, and Niels Henrik Borch. 2003. Fate of terrigenous dissolved organic matter (DOM) in estuaries: Aggregation and bioavailability. Ophelia 57: 161-176. https://doi.org/10.1080/00785236.2003.10409512.

Swarth, Christopher W., Patricia Delgado, and Dennis F. Whigham. 2013. Vegetation dynamics in a tidal freshwater wetland: A longterm study at differing scales. Estuaries and Coasts 36: 559-574. https://doi.org/10.1007/s12237-012-9568-x.

Tzortziou, Maria, Christopher L. Osburn, and Patrick J. Neale. 2007. Photobleaching of dissolved organic material from a tidal marshestuarine system of the Chesapeake Bay. Photochemistry and Photobiology 83: 782-792. https://doi.org/10.1111/j.1751-1097. 2007.00142.x.

Tzortziou, Maria, Patrick J. Neale, Christopher L. Osburn, J. Patrick Megonigal, Nagamitsu Maie, and Rudolf Jaffé. 2008. Tidal marshes as a source of optically and chemically distinctive colored dissolved organic matter in the Chesapeake Bay. Limnology and Oceanography 53: 148-159. https://doi.org/10.4319/lo.2008.53.1.0148.

Tzortziou, Maria, Patrick J. Neale, J. Patrick Megonigal, Crystal Lee Pow, and Megan Butterworth. 2011. Spatial gradients in dissolved carbon due to tidal marsh outwelling into a Chesapeake Bay estuary. Marine Ecology Progress Series 426: 41-56. https://doi.org/ 10.3354/meps09017.
U.S. Geologic Survey, National Geospatial Program. 2020. USGS National Hydrography Dataset Best Resolution (NHD) for Hydrologic Unit (HU) 4 - 0206. U.S. Geological Survey.

Vähätalo, Anssi V., and Robert G. Wetzel. 2008. Long-term photochemical and microbial decomposition of wetland-derived dissolved organic matter with alteration of $13 \mathrm{C}: 12 \mathrm{C}$ mass ratio. Limnology and Oceanography 53: 1387-1392. https://doi.org/ 10.4319/lo.2008.53.4.1387.

Vodacek, Anthony, Neil V. Blough, Michael D. DeGrandpre, Michael D. DeGrandpre, and Robert K. Nelson. 1997. Seasonal variation of CDOM and DOC in the Middle Atlantic Bight: Terrestrial inputs and photooxidation. Limnology and Oceanography 42: 674-686. https://doi.org/10.4319/lo.1997.42.4.0674.

Walker, Sally A., Rainer M. W. Amon, and Colin A. Stedmon. 2013. Variations in high-latitude riverine fluorescent dissolved organic matter: A comparison of large Arctic rivers. Journal of Geophysical Research: Biogeosciences 118: 1689-1702. https://doi.org/10. 1002/2013JG002320.

Wang, Yingying, Frederik Hammes, Nico Boon, and Thomas Egli. 2007. Quantification of the filterability of freshwater bacteria through $0.45,0.22$, and $0.1 \mu \mathrm{m}$ pore size filters and shape-dependent enrichment of filterable bacterial communities. Environmental Science \& Technology 41: 7080-7086. https://doi.org/10.1021/es0707198.

Wang, Xuchen, Robert F. Chen, Jaye E. Cable, and Jennifer Cherrier. 2014. Leaching and microbial degradation of dissolved organic matter from salt marsh plants and seagrasses. Aquatic Sciences 76: 595-609. https://doi.org/10.1007/s00027-014-0357-4.

Weishaar, James L., George R. Aiken, Brian A. Bergamaschi, Miranda S. Fram, Roger Fujii, and Kenneth Mopper. 2003. Evaluation of specific ultraviolet absorbance as an indicator of the chemical composition and reactivity of dissolved organic carbon. Environmental Science \& Technology 37: 4702-4708. https://doi.org/10. 1021/es030360x.

Wickland, Kimberly P., Jason C. Neff, and George R. Aiken. 2007. Dissolved organic carbon in Alaskan boreal forest: Sources, chemical characteristics, and biodegradability. Ecosystems 10: 1323-1340. https://doi.org/10.1007/s10021-007-9101-4.

Wiegner, Tracy N., and Sybil P. Seitzinger. 2004. Seasonal bioavailability of dissolved organic carbon and nitrogen from pristine and polluted freshwater wetlands. Limnology and Oceanography 49: 1703-1712. https://doi.org/10.4319/lo.2004.49.5.1703.

Williamson, C. E., and P. J. Neale. 2009. UV radiation, in Encyclopedia of Inland Waters, edited by G. Likens, 705-714, Elsevier, Oxford. https://doi.org/10.1016/B978-012370626-3.00076-4.

Yamashita, Youhei, Rudolf Jaffé, Nagamitsu Maie, and Eiichiro Tanoue. 2008. Assessing the dynamics of dissolved organic matter (DOM) in coastal environments by excitation emission matrix fluorescence and parallel factor analysis (EEM-PARAFAC). Limnology and Oceanography 53: 1900-1908. https://doi.org/ 10.4319/lo.2008.53.5.1900.

Yamashita, Youhei, Nagamitsu Maie, Henry Briceño, and Rudolf Jaffé. 2010a. Optical characterization of dissolved organic matter in tropical rivers of the Guayana Shield, Venezuela. Journal of Geophysical Research: Biogeosciences 115: G00F10. https://doi. org/10.1029/2009JG000987.

Yamashita, Youhei, Leonard J. Scinto, Nagamitsu Maie, and Rudolf Jaffé. 2010b. Dissolved organic matter characteristics across a subtropical wetland's landscape: Application of optical properties in the assessment of environmental dynamics. Ecosystems 13: 1006-1019. https://doi.org/10.1007/s10021-010-9370-1.

Yamashita, Youhei, Brian D. Kloeppel, Jennifer Knoepp, Gregory L. Zausen, and Rudolf Jaffé. 2011. Effects of watershed history on dissolved organic matter characteristics in headwater streams. Ecosystems 14: 1110-1122. https://doi.org/10.1007/ s10021-011-9469-z. 